\title{
Advocacy and Political Convergence under Preference Uncertainty
}

\author{
Ernesto Reuben, ${ }^{*}$ Christian Traxler, ${ }^{\dagger}$ and Frans van Winden ${ }^{\ddagger}$
}

This version: June 2015

\author{
Forthcoming in the \\ European ECONOMiC Review
}

\begin{abstract}
We study the formation of advocacy groups and how they can impact policy outcomes by revealing information about voters' preferences to uninformed political candidates. We conduct a laboratory experiment based on a two-candidate spatial electoral competition setting where the policy preferences of voters are (initially) unknown and change over time. In the control treatment candidates learn about the preferred policy of the median voter through the voting outcome of elections. In the advocacy treatments, voters can organize themselves into advocacy groups in order to reveal their policy preferences. We find that voters often overcome the collective action problem of forming an advocacy group. In fact, we observe the formation of both informative advocacy groups, which convey new information, and uninformative advocacy groups, which do not. Overall, advocacy groups significantly speed up the convergence to the preferred policy of the median voter. However, advocacy does not lead to higher earnings as the gains from faster convergence are offset by the costs of group formation.
\end{abstract}

JEL Codes: H41, C92, D63

Keywords: Advocacy groups $\cdot$ Information transmission $\cdot$ Political convergence $\cdot$ Voting $\cdot$ Median voter $\cdot$ Preference uncertainty

${ }^{*}$ Columbia University and IZA. Address: Columbia Business School, 705 Uris Hall, 3022 Broadway, New York, NY 10027, USA. Email: ereuben@columbia.edu.

${ }^{\dagger}$ Hertie School of Governance and CESifo. Address: Hertie School of Governance, Friedrichstrasse 180, 10117 Berlin, Germany. Email: traxler@hertie-school.org.

${ }^{\ddagger}$ University of Amsterdam and CESifo. Address: Department of Economics, Roetersstraat 11, 1018 WB Amsterdam, the Netherlands. Email: F.A.A.M.vanWinden@uva.nl. 


\section{Introduction}

Voting plays a key role in the decision-making of democratic public or private organizations, like states or unions, that care about the aggregate welfare of their constituents. Even when decision making is delegated, electoral competition between policymaking candidates can generate optimal policies that maximize social welfare (Mueller, 2003). In this respect, a crown jewel in the theory of voting is the median voter theorem, which states that the ideal point of the median voter in the policy space will be decisive (Downs, 1957). In deriving this result, theoretical models often make strong assumptions concerning the available information. In particular, perfect information about the preferences of both candidates and voters or about the probability distribution of a candidate bias among the latter are often assumed (see Persson and Tabellini, 2002). Democratic environments, however, are typically characterized by huge information problems and asymmetries. Not only are policymakers and individual voters usually unaware of the distribution of policy preferences in the electorate, but such preferences can and often do change over time, sometimes in a dramatic fashion. Research on the channels through which information about policy preferences are transferred in such environments is of great relevance to our understanding of democratic governance under preference uncertainty. This paper contributes to this research by investigating the role of spontaneous collective action involving advocacy as a means of preference revelation that, in addition to voting, can help policymakers find optimal social policies.

Advocacy by unorganized grassroots movements has recently attracted great attention, in particular, through its successful use by political candidates (like US president Obama) and their role in the Arab Spring revolts. Advocacy groups have also been credited for having a strong influence on legislation and government policies concerning, e.g., human rights and environmental politics (e.g., Keck and Sikkink, 1998). More recently, it is even argued that new communication technologies that greatly reduce the costs of advocacy have fundamentally changed how citizens, political parties, and policymakers interact (e.g., Obar et al., 2012; Hamby, 2013). This purportedly increased importance of independent advocacy groups calls for more research on the formation of such groups and on the welfare consequences of their influence on policy outcomes. ${ }^{1}$ Because of the complex environments in which advocacy groups emerge, studying their impact in the field is fraught with difficulties. For this reason, we complement field research by conducting a laboratory experiment that offers a controlled environment to analyze several important aspects of advocacy that are otherwise hard to measure and evaluate.

The experiment is based on a two-candidate spatial electoral competition setting. Our main focus is on the positioning of the candidates in a one-dimensional policy space where the (singlepeaked) policy preferences of the voters are not only unknown to the candidates but also change over time. In a control treatment, the only information available to candidates is the voting outcome of elections. In the advocacy treatments, we give voters the opportunity to organize

\footnotetext{
${ }^{1}$ An "advocacy group" is generally understood as a group that attempts to influence public policy through activities such as demonstrations, media campaigns, public speaking, online petitions, and conducting exit polls. Advocacy groups are distinct from political parties in that they do not aim to govern formally (Richardson, 1993).
} 
themselves at a cost into advocacy groups. Once formed, an advocacy group reveals to the candidates (and the electorate as a whole) information about the number of voters located at their respective location in the policy space. Within this experimental framework we study three key questions. Will voters form advocacy groups? If so, will advocacy groups help candidates to converge to the median voter's location? And, does the electorate as a whole benefit from advocacy groups?

Our experimental setup captures two important asymmetries present in settings where advocacy groups can play an important role. The first is an informational asymmetry between candidates and voters, which gives voters a reason to form groups in order to transmit information to candidates. Specifically, voters know how many others share their own policy preference (but are unaware of how voters with different policy preferences are distributed). ${ }^{2}$ The second asymmetry concerns the costs of revealing information through advocacy. In the experiment, the formation of a group reveals the precise number of voters in that location in the policy space. However, the cost of forming the group is borne only by those who initiate it. ${ }^{3}$ This setup mimics situations where a few activists can decide to take the lead in revealing the policy preferences of many, which introduces a collective action problem and opens the door to free-riding. ${ }^{4}$

Although advocacy groups reveal information about voter preferences, it is not clear that it is always in the best interest of voters to form an advocacy group. In addition to the costs discussed above, an individual's potential benefits from more public information depend on her location relative to the median voter as well as the candidates' responses to the revealed information. Since voters face considerable uncertainty about their policy preference compared to those of others in the electorate, forming an advocacy group is not a straightforward decision.

Whether advocacy groups speed up convergence to the preferred policy of the median voter depends to a large extent on which advocacy groups form. On one extreme, if all voters organize into advocacy groups, candidates will have perfect information concerning voter preferences and convergence to the median voter should occur immediately. However, if advocacy groups are more likely to form in distant locations vis-à-vis the media voter and candidates fail to take this into account, then advocacy groups could slow down policy convergence. Finally, the net social welfare consequences of allowing people to advocate will depend on whether the potential benefits from quicker convergence outweigh the costs of group formation.

Our main findings are the following. First, voters make frequent use of the costly option to form an advocacy group, and, interestingly, the more so the larger the number of other voters who are expected to participate. Second, advocacy groups significantly speed up the convergence

\footnotetext{
${ }^{2}$ Assuming that voters have an information advantage over politicians regarding the number of voters who have similar policy preferences seems justified as people interact more frequently with like-minded others.

${ }^{3}$ Examples of such costs asymmetries include demonstrations and online petitions where those who organize them often incur high costs compared to those who attend or sign them.

${ }^{4}$ In our study the decision to form an advocacy group is taken simultaneously by each voter and just one individual is needed to form a group. In this respect, the advocacy-group formation part of our study differs from the wellestablished experimental literature on linear public goods (for a recent survey, see Chaudhuri, 2010) and is more closely related to studies of best-shot public goods (e.g., Kroll et al., 2007; Cherry et al., 2013) or collective action games (Sheremeta, 2011).
} 
to the preferred policy of the median voter and help to quickly equilibrate after a shock to the preference distribution. Third, informative groups, i.e., groups that convey new information about the distribution of preferences, but also uninformative advocacy groups are formed. These group types show different determinants: only informative groups are responsive to the expected pecuniary benefits from organizing; uninformative groups are more sensitive to the costs of group formation. The latter groups also become less frequent over time and seem to be partly triggered by a motive of "expressive advocacy" (comparable to expressive voting; Brennan and Buchanan, 1984). Fourth, in addition to the information revealed by the election outcomes, candidates rely on the information generated by advocacy groups, however, they do not respond to uninformative groups. Finally, we find that, given the parameters in the experiment, there are no higher pecuniary benefits to voters from advocacy as the average pecuniary gain from faster convergence are offset by the costs of forming groups.

Our paper builds on previous studies that investigate mechanisms that help ameliorate informational problems in political decision-making. Starting with the work of McKelvey and Ordeshook (1984, 1985a,b) and Collier et al. (1987), one branch of this literature demonstrates that, in spite of the theoretical difficulties of analyzing elections with considerable preference uncertainty in spatial policy spaces, simple behavior like retrospective voting often results in convergence to the policy preferred by the median voter (for a review, see Palfrey, 2013). Within this literature, our paper is more closely related to studies that investigate additional institutional channels of information transfer like opinion polls, endorsements, and campaign contributions by lobby groups (e.g., Williams, 1994; Sadiraj et al., 2006; Sinclair and Plott, 2012). Our study complements this line of research by adding the possibility of preference revelation by voters through the endogenous formation of advocacy groups.

Another strand of the literature on political decision-making focuses on the role of information for the decision to vote. Studies in this area generally assume voting is costly and therefore information on the preferences and costs of the electorate are relevant to individuals when they decide whether they want to turn out (examples include Levine and Palfrey, 2007; Battaglini et al., 2009; Großer and Schram, 2010; Morton and Tyran, 2011; Tyszler and Schram, 2013). Although voting is compulsory and strategic voting is unlikely in our experiment, there is nevertheless a parallel with this line of work in that participating in an advocacy group is costly and voters benefit if others with similar policy preferences incur the participation costs. However, in our study the benefits of participation are not necessarily positive for voters with policy preferences that are far from those of the median voter.

Lastly, our work is related to the literature on information transmission to policymakers by interest groups inspired by the seminal work of Crawford and Sobel (1982). This work, however, focuses on the strategic incentive of well-informed interest groups to misrepresent information to uninformed policymakers (a review of this literature is provided by Grossman and Helpman, 
2001). ${ }^{5}$ By comparison, candidates and advocacy groups in our setting are equally uninformed about the preferences of the rest of the electorate, which is arguably a more realistic assumption in many settings of interest.

The organization of the paper is further as follows. Section 2 concerns the design and procedures of the experiment, while Section 3 deals with theoretical considerations and hypotheses. Section 4 presents the results, focusing on policy dynamics, the behavior of voters and candidates, and the welfare implications of advocacy groups. Section 5 concludes.

\section{The Experiment}

In the experiment, two candidates compete for votes in a one dimensional policy space with an Euclidean representation of the policy issue. The electorate consists of 19 voters who are located throughout the policy line. Subjects are either in the role of a voter or a candidate and they retain this role throughout the 24 periods of the experiment. In each period $t$, one of the two candidates plays the role of the incumbent and the other candidate the role of the challenger. The incumbent is the candidate who won the election in period $t-1$ and the challenger is the candidate who lost that election. The challenger's decision in period $t$ consists of choosing a location $\ell_{t}^{C}$ on a policy line with 15 locations. He can choose any location on the policy line except for the one occupied by the incumbent, $\ell_{t}^{I}$. In any period $t>1$, the incumbent is bound to the location at which he won in the previous period. In the first period, the role of the incumbent is randomly assigned and his location is exogenously fixed at the midpoint, $\ell_{1}^{I}=8$. After the challenger chooses $\ell_{t}^{C}$, all subjects observe the candidates' locations: $\ell_{t}^{C}$ and $\ell_{t}^{I}$.

At this point, voters simultaneously cast their vote for one of the two candidates. Voting is not costly and abstention is not feasible. Thereafter, all players are informed about the number of votes received by the challenger and the incumbent. The candidate with a simple majority (i.e., 10 or more votes) wins the election. The winning candidate earns 75 points and becomes the incumbent in the following period. The losing candidate gets 0 points and becomes the next period's challenger. Hence, the candidates' payoffs only depend on whether or not they win the election and not on the location of the winner. Each voter has a single-peaked payoff function that depends on the voter's location (i.e., her most preferred policy) and the location of the candidate that wins the election. Specifically, denoting the location of voter $i$ in period $t$ as $\ell_{i t}$ and the location of the winning candidate as $\ell_{t}^{w}$, the voter's period payoff is given by

$$
\pi_{i t}=a-b\left|\ell_{t}^{w}-\ell_{i t}\right|, \quad a, b>0
$$

In the experiment $a=70$ and $b=5$ points.

\footnotetext{
${ }^{5}$ Recent experimental work related to this framework includes Gneezy (2005), Sánchez-Pagés and Vorsatz (2007, 2008), Hao and Houser (2013), and Jiang (2013).
} 


\section{Distribution of voters}

It is common knowledge that there are 19 voters with single-peaked preferences distributed over the 15 locations. Hence, there exists a unique location in each period $t$ - the location of the median voter - that is preferred by a majority of voters over any other location in the policy line. However, the voters' preferred policy - their location $\ell_{i t}$ - does not stay constant throughout the experiment. Subjects are informed that there will be two preference shocks and that a shock changes the location of all voters, but they do not know in which periods the preference shocks will take place. ${ }^{6}$ The experiment implemented preference shocks at the beginning of periods 10 and 18, respectively. In the following, we will therefore focus our analysis on three distinct phases: phase 1 corresponds to periods before the first preference shock (periods 1-9), phase 2 to periods between the first and second shock (periods 10-17), and phase 3 to periods after the second preference shock (periods 18-24). Figure 1 illustrates the distribution of voters over the policy line for each phase. In phase 1, we implement a distribution with a median voter at location 12 (see the dark-red bar in Figure 1). Phase 2 has the winning location at location 7 . Finally, in phase 3 , the median voter is at location 3.

The experimental instructions do not contain any indication of how the 19 voters are distributed across the policy space. Thus, subjects initially do not know the location of the median voter. Voters do have some private information though. Each voter knows her own location and how many other voters share it. ${ }^{7}$ However, voters have no private information concerning the location of the remaining electorate. Candidates have no private information at all.

\section{Treatments}

The distribution of voters and the timing of the preference shocks discussed above are kept constant throughout the experiment. As treatment conditions we varied the channels and cost at which publicly-available information concerning the distribution of voters is transmitted. In our control treatment, henceforth NA (No Advocacy), subjects only obtain information via the election. Thus, when choosing a new location, challengers can base their decision only on previous election outcomes. ${ }^{8}$

In our other treatments, henceforth $A G$ (Advocacy Groups), we allow for the endogenous formation of advocacy groups as an additional channel of information transmission. Before the challenger chooses a location, voters simultaneously decide on whether or not to form an advocacy

\footnotetext{
${ }^{6}$ Subjects knew that the locations of voters would remain constant for at least two periods. That is, there are no consecutive preference shocks. In addition, voters knew that any other voters sharing their new location would be subjects with whom they did not share a location in previous phases.

${ }^{7}$ For example, in phase 1, every voter at location 6 knows that two other voters are at this location. Admittedly, assuming that voters know the total number of other voters who share their policy preference is a strong assumption. It would be more realistic to assume that voters have imperfect information concerning the number of other voters in their location. However, this additional layer of uncertainty would complicate the game and, given the limited size of the electorate, would nevertheless result in a very similar setup.

${ }^{8}$ For example, if a candidate at location 9 wins against one at location 8 , this implies that the median voter was located in one of the locations $[9,15]$.
} 
Phase 1

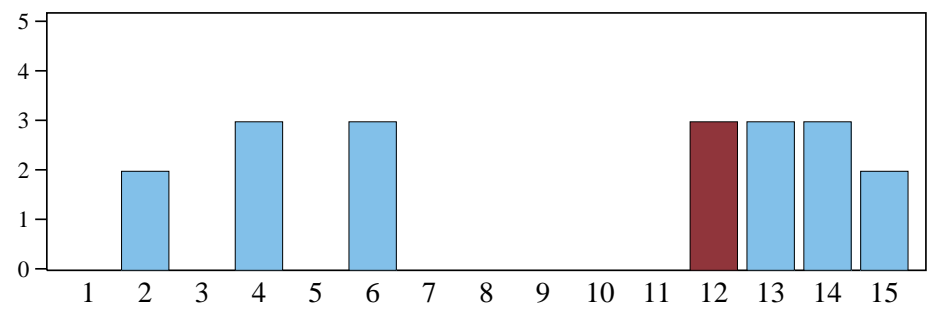

Phase 2

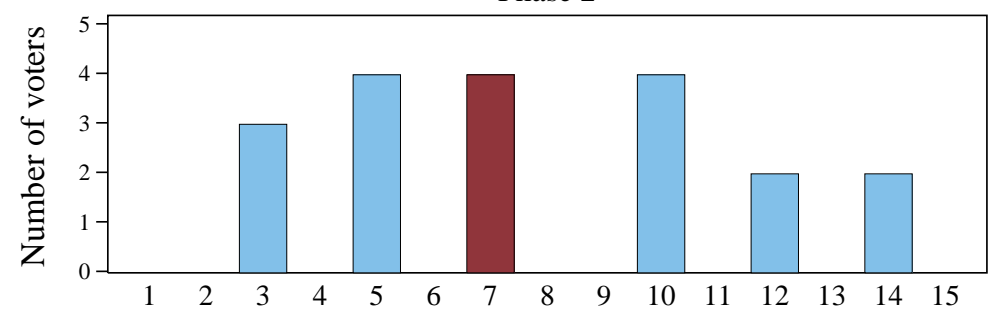

Phase 3

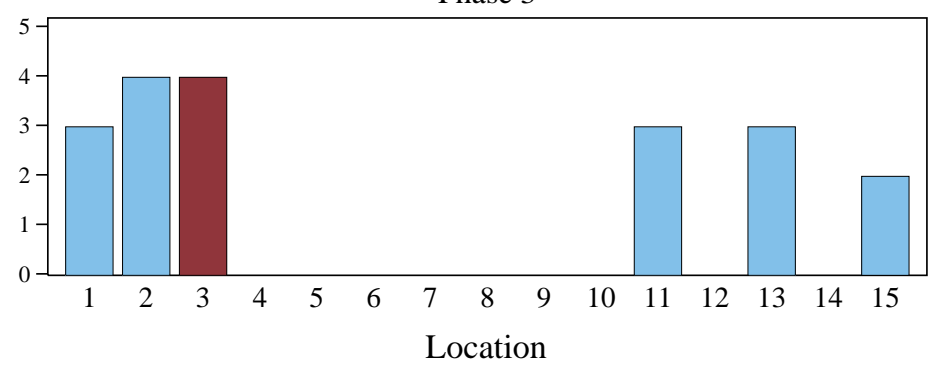

Figure 1: Distribution of voters over the policy line in phase 1 (periods 1-9), phase 2 (periods 10-17), and phase 3 (periods 18-24). The median voter's location for each phase is indicated by the dark (red) bars.

group. If at least one voter in a given location $\ell^{\prime}$ initiates a group, the candidates and all other voters are informed about the exact number of voters at location $\ell^{\prime}$ in period $t .{ }^{9}$ Figure 2 summarizes the sequence of events and choices within each period of the $A G$ treatments (above and below the line) and the NA treatment (only above the line).

The formation of advocacy groups (potentially) provides candidates with additional information on the distribution of voters. A challenger can now base his location choice on past election results and the information revealed by the advocacy groups. However, advocacy is not free; forming an advocacy group in period $t$ costs a total of $c$ points. The cost is shared equally by all voters in a location that form a group (e.g., if two voters in location $\ell^{\prime}$ form a group then each pays $\frac{c}{2}$ points). We implemented three different advocacy group treatments, which we call AG12, AG18

\footnotetext{
${ }^{9}$ By revealing the total number of voters in the location, we are modeling situations where there are important costs asymmetries between those who organize the formation of advocacy groups and those who simply partake in them. An alternative setup would be one in which subjects first decide whether to form an advocacy group at a large cost and then decide whether they want to be part of the group at a lower cost. In this case, only those who take part of the group would be revealed to the candidates. This alternative setup is more realistic but also more complicated. For this reason we opted for our simplified setup, which already captures the basic features of advocacy group formation.
} 


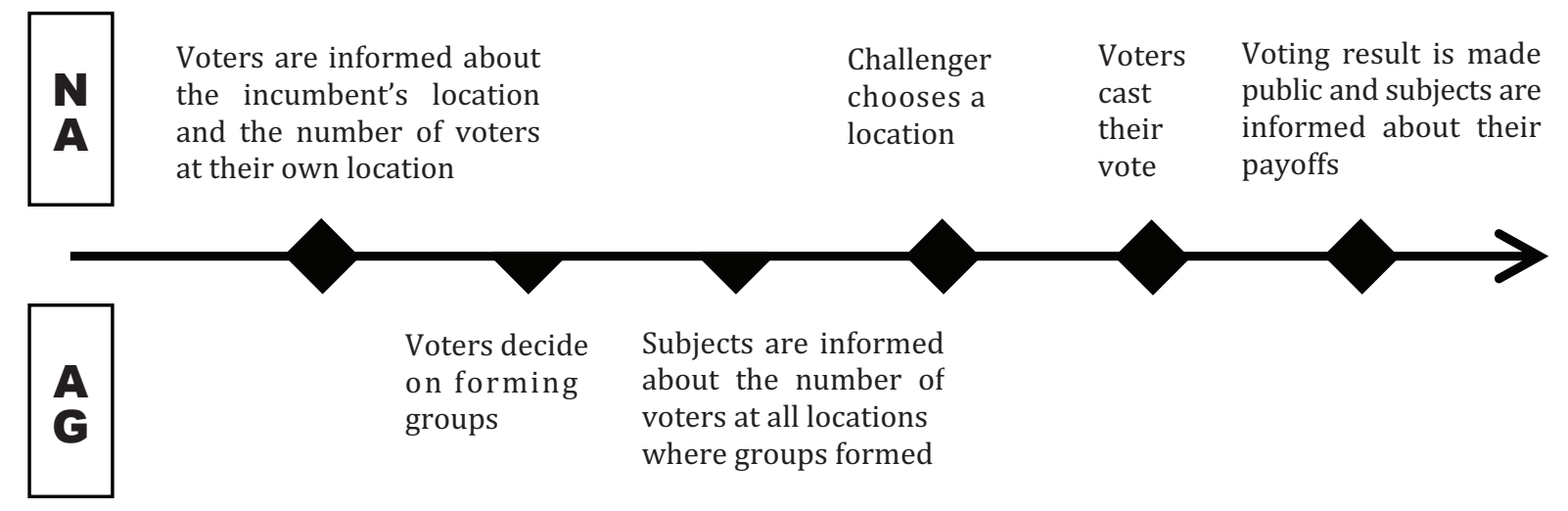

Figure 2: Time line of the events and choices within a period for the NA treatment (only entries above the line) and the $A G$ treatments (above and below the line).

and AG24. Each treatment involves different costs of forming an advocacy group: $c=12$ in AG12, $c=18$ in $A G 18$, and $c=24$ in $A G 24 .^{10}$

In order to better understand the motivations behind the formation of advocacy groups, we also elicit the voters' expectations concerning the costs and benefits of forming a group. After subjects made their choice to form or not form a group, we ask each voter for: (i) the expected number of other voters who will form an advocacy group at the voter's preferred location, (ii) the expected location of the winning candidate if a group is formed at the voter's location, and (iii) the expected location of the winning candidate if a group is not formed at the voter's location. ${ }^{11}$ We elicit these expectations in the initial three periods as well as in the first two periods after each preference shock (i.e., periods $1-3,10-11$, and 18-19). ${ }^{12}$

Finally, after the 24 periods of the game, subjects filled out a debriefing questionnaire that included questions on demographic characteristics, political participation, and policy preferences. Among others, subjects had to answer the following three questions on seven-point Likert scales: "Do you participate in political demonstrations?", "Do you vote in national and municipal elections?" (from $1=$ never to $7=$ always), and "One's general political stance can be described (more or less) as left or right. Where do you place yourself on the political scale?" (from $1=$ left to $7=$ right).

\footnotetext{
${ }^{10}$ For a discussion on these cost parameters, see Section 3 (Conjecture 4 ).

${ }^{11}$ We opted for non-incentivized belief elicitation as we did not want to distract subjects who are playing an already complex game with an incentivized elicitation technique. Moreover, in some cases beliefs cannot be incentivized because they are contingent on a subject's own choices (e.g., asking a voter who already decided to form an advocacy group for the expected location of the winning candidate if no group is formed). To the best of our knowledge, studies comparing incentivized versus non-incentivized beliefs concerning the actions of others have not found that the latter are biased (e.g., Friedman and Massaro, 1998; Sonnemans and Offerman, 2001), even though incentivized beliefs were found to be more accurate (Gächter and Renner, 2010). A detailed discussion is provided by Blanco et al. (2010).

${ }^{12}$ We did not elicit beliefs in all 24 periods because, due to the relative stability of the voters' preferences, we expected that most advocacy groups would be formed at the beginning of the game and shortly after each shock.
} 


\section{Experimental procedures}

We ran four sessions with 21 subjects ( 2 candidates and 19 voters) for each treatment (NA, AG12, AG18 and AG24). In total, 336 subjects (208 men and 128 women) participated in the computerized experiment, which was conducted in the CREED laboratory of the University of Amsterdam. The subjects were students from all fields, half of whom were economics/business students. On average, subjects earned 23.50 Euros and one session lasted approximately 90 minutes. Appendix A contains a detailed description of the experimental procedures.

\section{Behavioral Discussion}

To provide a structure for our analysis of the experimental results, we now discuss the incentives faced by subjects in the different roles. We first consider the voters' behavior.

\section{Voting}

For voter $i$ in period $t$, voting for the candidate who is closer to $\ell_{i t}$ (weakly) increases that candidate's chance of winning - irrespective of the other voters' locations and behavior. Sincere voting thus maximizes $i$ 's expected payoff in a given period.

By contrast, the incentives to vote strategically for the candidate who is further away from $\ell_{i t}$ are ambiguous. Since convergence to the median voter location is bound to occur even if candidates have no initial information on voter preferences (see McKelvey and Ordeshook, 1985a), the benefits of strategic voting are limited to changing the speed of convergence. However, since voters start with very little information about their location vis-à-vis the median voter, it is initially unclear whether they would benefit from such a change. For this reason, we do not expect to observe a significant number of subjects voting strategically. ${ }^{13}$

Conjecture 1 Voters vote sincerely in the sense of voting for the candidate who is closer to their preferred location in the current period.

\section{Advocacy group formation}

A payoff-maximizing voter will tradeoff the expected costs and benefits of forming a group. Benefits emerge if voter $i$ expects that the formation of an advocacy group at her location $\ell_{i t}$ will make the challenger move closer to $\ell_{i t}$ (and win) as compared to the case without the group. ${ }^{14}$ If advocacy groups produce quicker convergence to the median voter's location, a majority of voters have an incentive to form groups. One might thus expect to see at least some groups being formed.

\footnotetext{
${ }^{13}$ This is not to say that strategic voting does not occur in experiments. Battaglini et al. (2009) and Morton and Tyran (2011) demonstrate that subjects do vote strategically when the incentives to do so are clear.

${ }^{14}$ The expected benefit from a group are further shaped by the expectations regarding the location of the median voter, the likelihood that other voters form advocacy groups, the subsequent responses of the candidates (see below), and the expected number of periods until the median voter's location changes (or the game ends).
} 
Recall that (i) the formation costs are only shared among those voters who decide to form a group at location $\ell$ and that (ii) the information revealed by the group does not depend on the number of voters bearing the costs. Voters who form a group therefore generate a positive externality for other voters at their location, ${ }^{15}$ which introduces the possibility of free-riding: if voter $i$ expects at least one other voter at $\ell_{i t}$ to form a group, she has a clear incentive not to invest in group formation. The decision to form a group thus has a collective action element that might hinder the formation of advocacy groups. ${ }^{16}$ However, since there is considerable evidence demonstrating that individuals often solve collective action problems (see Camerer, 2003), we expect that some advocacy groups will be formed, particularly when the (perceived) benefits of doing so are large. Clearly, for a given set of beliefs, the net expected benefits of forming an advocacy group are lower the higher the costs of doing so. ${ }^{17}$ Consequently, we expect more groups to form at lower group-formation costs. It is also clear that there is a larger incentive to form advocacy groups in the early periods of a phase, since voters can then expect to benefit from the faster convergence for more periods.

Concerning the number of voters at a given location $\ell$, one might expect the likelihood of a group formation to be increasing in the number of voters. Advocacy groups at highly populated locations reveal more information and, plausibly, are more successful to attract challengers (relative to groups at less populated locations). The expected benefits from forming a group would then increase with the number of voters at $\ell$. However, one might also argue that locations with many voters face more difficulties to solve the collective action problem and are therefore less likely to form a group. ${ }^{18}$ It is therefore unclear whether we should observe more or fewer groups being formed at highly populated locations. Lastly, one might argue that voters at locations that are relatively far away from the incumbent have a higher incentive to form a group because in the event that the median voter is close to their location they have more to gain from quicker convergence than voters with a similar belief who are close to the incumbent.

Conjecture 2 There is active advocacy group formation. More groups are formed at lower costs of doing so, at earlier periods within a phase, and at locations with a greater distance to the incumbent.

\footnotetext{
${ }^{15}$ In addition to the "location-specific" externality, there is also a "global" externality on the whole electorate, as advocacy groups affect the pace of convergence. As long as advocacy groups accelerate convergence, from which a majority of voters benefit, this global externality is always positive.

${ }^{16}$ It is important to note that, depending on the relative difference between the cost and benefit of forming an advocacy group, the decision to form a group is not necessarily dominated by that of not forming a group, which would make the group-formation process more akin to a Hawk-Dove game than to a prisoners' dilemma. For example, if two voters in a given location agree that the benefit of forming an advocacy group equals $\pi^{G}$ and the cost of doing so is $c$, then the group formation process has a Hawk-Dove game structure if $\pi^{G}>c$ and a prisoners' dilemma structure if $\frac{1}{2} c<\pi^{G}<c$.

${ }^{17}$ For instance, if the formation of a group is expected to result in the winning candidate being three locations closer, the expected gain would be $3 b=15$ points. If no other voter from the own location is expected to form the group, forming a group would then, ceteris paribus, be the expected payoff-maximizing action in AG12 $(c=12<15)$ but not in AG18 or AG24.

${ }^{18}$ Experimental evidence from public good games does not support this idea (e.g., Isaac et al., 1994).
} 


\section{Location choice of the challenger}

As long as voters vote sincerely and the challenger does not always choose the same (losing) location, there will be convergence towards the location of the median voter. The speed at which convergence occurs will depend on the available information concerning the distribution of voters along the policy line and on how candidates process this information. To illustrate this point, let us consider two intuitive strategies that candidates can use to make their location choice: the one-step and the multiple-step strategy.

The one-step strategy consists of the challenger always choosing the location immediately to the left or to the right of the incumbent's location, depending on the direction indicated by the last election outcome (in the first period, challengers randomize between jumping to the left or to the right). For example, if $\ell_{t}^{I}=8$ and $\ell_{t}^{C}=7$ and the incumbent wins in period $t$, then the challenger moves one step to the right of the incumbent in the next period, $\ell_{t+1}^{C}=9$. According to a multiple-step strategy, the challenger makes a random number of steps to the left or to the right of the winning location from the last period-accounting for all available information and again depending on the direction indicated by the electoral result (in the first period, the challenger randomizes between all locations). For the example from above, he would randomly pick one location $\ell_{t+1}^{C} \in\{9, \ldots, 15\}$. For a case where, e.g., $\ell_{t}^{C}=3$ and the incumbent wins with $\ell_{t}^{I}=8$, the challenger would randomly chooses $\ell_{t+1}^{C}$ from $\{4, \ldots, 7,9, \ldots, 15\} .{ }^{19}$

The one-step strategy is not only very simple; in a one-shot game, it is also the challenger's dominant strategy as it makes him win (if the incumbent is not yet at the median voter's location). In this sense, it is a myopic best-response. In a non-final period of a repeated game, the one-step strategy delivers a certain win in the current period but is not necessarily dominant: taking one step can be costly since the chosen location might not be the location of the median voter, which gives the next period's challenger the opportunity to hit the median voter's location and win all subsequent elections (until the end of the phase, i.e., when the winning location changes). The multiple-step strategy implies that a challenger potentially makes several steps towards the expected location of the median voter. In contrast to the one-step policy, this will lower the challenger's chance of winning the current period's election. However, the strategy can increase the probability of picking exactly the location of the median voter (and winning all remaining elections in the phase) and thereby the speed of convergence. ${ }^{20}$

If there is little information about the distribution of voters, (risk averse) challengers might find the one-step strategy appealing as it delivers at least one certain win. Ceteris paribus, the tradeoff between the one-step and the multiple-step strategy is the same in all treatments. However, if advocacy groups are formed in the $A G$ treatments, challengers potentially have more information on the distribution of voters in $A G$ as compared to $N A$. The additional information reduces the risks

\footnotetext{
${ }^{19}$ Certainly, one can come up with many variations of a multiple-step strategy. We selected this one to serve as a benchmark as it is relatively simple. It guarantees that the median voter's location is reached in spite of preference shocks and it incorporates the intuition that one ought to move in the direction of the winner.

${ }^{20}$ In Appendix B we provide a more detailed discussion of this case.
} 
associated with the multiple-step strategy, which makes it relatively more attractive. ${ }^{21}$ Moreover, if advocacy groups form in the very first period, challengers might be more likely to pick the side of the incumbent where the median voter is located instead of having a $50 \%$ chance of guessing correctly. We therefore expect larger steps and quicker convergence under the $A G$ treatment if (sufficiently many) advocacy groups are indeed formed.

Conjecture 3 (a) Candidates converge to the location of the median voter in all treatments. (b) There is faster convergence to the median voter's location in the AG treatments compared to the NA treatment.

\section{Overall Payoffs}

Since the sum of all voters' payoffs is maximized at the median voter's location, faster convergence is clearly beneficial from a total payoff-maximizing perspective. The impact of advocacy groups therefore depends on the benefits from quicker convergence, net of group formation costs. If people hold overly optimistic expectations about the benefits, "excessive" group formations with negative effects on earnings might occur. However, there is plenty of scope for advocacy groups to increase aggregate payoffs. For instance, if we use the one-step strategy as a benchmark, there is a loss of 427.5 points (22.5 points per voter) compared to a hypothetical case of immediate convergence in the first period of each phase. In principle, such immediate convergence could be achieved if an advocacy group is formed in each non-empty location in each of the three phases (i.e., 7 advocacy groups in phase 1, 6 in phase 2, and 6 in phase 3, which gives a total of 19 advocacy groups, see Figure 1). As compared to the one-step strategy without groups, this level of group formations (and assuming that it implies immediate convergence) would increase overall payoffs in AG12 and AG18 but not in $A G 24 .{ }^{22}$ If the number of advocacy groups being formed is just enough to reveal the location of the median voter ( 4 groups in phase 1, and 3 groups in phases 2 and 3 ) then there would be payoff gains in all $A G$ treatments.

Conjecture 4 Total payoffs are at least as high in the AG treatments as compared to the NA treatment.

\section{Results}

This section discusses the experiment's results. We first examine the speed at which candidates converge to the location of the median voter. Thereafter we study the behavior of voters and can-

\footnotetext{
${ }^{21}$ To illustrate this point, consider the distribution of voters in phase 1 (see Figure 1). For instance, if advocacy groups form at locations $12-15$, the median voter's location would be revealed to the candidates, and the challenger can immediately jump to location 12. Even for cases where the location of the median voter is not precisely identified, the information revealed by advocacy groups ought to help challengers to form more accurate expectations of the distribution of voters and hence make them more willing to take larger steps towards the (expected) median voter's location. In turn, this will speed up convergence.

${ }^{22} \mathrm{Put}$ differently, across the three phases, a maximum of 35 advocacy groups can form in AG12 $(35 \times 12<427.5)$, 23 in $A G 18(23 \times 18<427.5)$, and 17 in $A G 24(17 \times 24<427.5)$ without producing a payoff loss from groups having formed.
} 


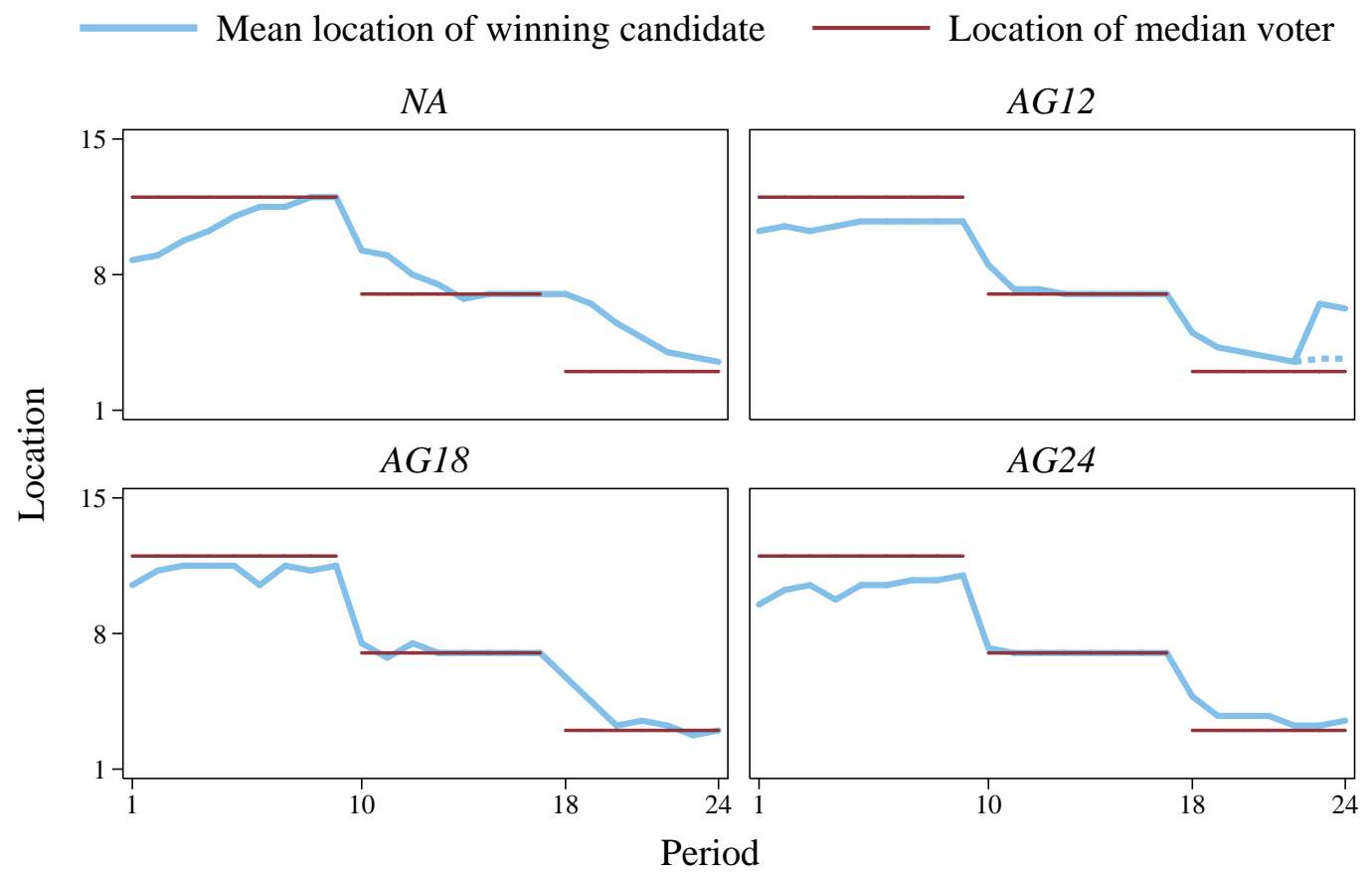

Figure 3: Mean location of the winning candidate (thick blue line) and the location of the median voter (thin red line) for every period in each of the four treatments. The dotted line in AG12 corresponds to the mean winning location excluding the outlier election (see Section 4.2).

didates which drives the aggregate outcome. The section concludes with the welfare implications of advocacy group formation.

\subsection{Convergence to the median voter}

Figure 3 provides us with a first impression of whether and how fast candidates converge to the location of the median voter. It depicts the location of the median voter and the mean location of the winning candidate in each treatment. In line with Conjecture 3.a, we observe that the winning candidate clearly converges towards the location of the median voter in all treatments. This result is also evident in Figure C.1 in Appendix C, which shows the convergence paths of each single session. Convergence in the NA treatment is in line with earlier studies that show that information concerning the vote tally is enough to produce movement towards the median voter (e.g., Collier et al., 1987; McKelvey and Ordeshook, 1990b). Figure 3 also suggests that, in line with Conjecture 3.b, there is faster convergence towards the median voter's location in the $A G$ treatments compared to NA. We explore this impression in more detail next.

A different way of measuring convergence is based on the absolute distance between the locations of the winning candidate and the median voter. Table 1 provides summary statistics for this distance for each treatment. In addition, the lower part of the table provides the mean and standard deviation one would obtain if candidates used one of the benchmark strategies described in Section 3: the one-step strategy (choosing the location immediately to the left/right of the in- 
Table 1: Mean distance between the locations of the winning candidate and the median voter. Standard deviations in parenthesis.

\begin{tabular}{lcccc}
\hline \hline & Overall & Phase 1 & Phase 2 & Phase 3 \\
\hline NA & $1.53(0.42)$ & $1.36(0.63)$ & $1.31(0.22)$ & $2.00(0.62)$ \\
All AGs & $0.88(0.53)$ & $1.31(1.08)$ & $0.17(0.18)$ & $1.15(0.62)$ \\
AG12 & $1.12(0.65)$ & $1.42(1.43)$ & $0.25(0.23)$ & $1.75(1.31)$ \\
AG18 & $0.66(0.58)$ & $0.89(0.99)$ & $0.22(0.16)$ & $0.86(0.71)$ \\
AG24 & $0.86(0.32)$ & $1.61(0.96)$ & $0.03(0.06)$ & $0.86(1.17)$ \\
\hline One-step strategy & $1.19(0.16)$ & $0.89(0.22)$ & $1.56(0.31)$ & $1.14(0.29)$ \\
Multiple-step strategy & $1.14(0.39)$ & $0.94(0.58)$ & $1.46(0.80)$ & $1.01(0.64)$ \\
\hline \hline
\end{tabular}

cumbent) and the multiple-step strategy (randomly choosing among the locations to the left/right of the loser of the last election).

On the whole, the data support conjecture 3.b: the mean distance between the winning candidate and the location of the median voter is 1.53 locations in $N A$, but only 0.88 locations in the $A G$ treatments. According to a Fligner-Policello robust rank order test (henceforth RRO; see Fligner and Policello, 1981), this latter distance is significantly lower than the former $(U=2.913$, $p \leq 0.024$; using session means as independent observations). ${ }^{23}$ A closer analysis shows that the treatment differences are mainly driven by the last two phases. While there is no significant difference in convergence between the $N A$ and the $A G$ treatments in phase $1(U=0.338)$, the $A G$ treatments show significantly faster convergence in phases 2 and $3(U=6.928, p \leq 0.006$, and $U=1.972, p \leq 0.100) .{ }^{24}$ When we compare the $N A$ to each $A G$ treatment separately, we find a significantly better convergence in AG18 $(U=2.502, p \leq 0.057)$ and AG24 $(U=4.484$, $p \leq 0.029)$. For $A G 12$, the distance to the median voter's location is not significantly different to $N A(U=1.027)$. Looking separately at each phase yields no significant differences in phase 1 $(U<1.017)$. By contrast, in phase 2 we find significantly faster convergence in each $A G$ treatment compared to $N A(U \geq 5.060, p \leq 0.029)$. Lastly, in phase 3 we observe significantly faster convergence in $A G 18(U=3.364, p \leq 0.057)$, AG24 $(U=1.586, p \leq 0.100)$, and no significant difference in $A G 12(U=0.239) .{ }^{25}$

Figure 4 offers further insights of why we see faster convergence in the $A G$ treatments. It plots the mean distance between the winning candidate and the location of the median voter over periods for the $N A$ (thin red lines) and the $A G$ treatments (thick blue lines). We can see that convergence towards the median voter's location happens more gradually in $N A$ as compared to the $A G$ treatments. In the latter, we typically observe an immediate jump close to the median voter's location in the first period of each phase (particularly in phases 2 and 3 ). In the $A G$ treatments, the median voter's location is reached in the first period of a phase $30.56 \%$ of the time and by the third period $63.89 \%$ of the time. In $N A$, there is not a single case where convergence

\footnotetext{
${ }^{23}$ Motivated by our directional hypotheses, the non-parametric results throughout the paper are presented with exact $p$-values of one-sided tests.

${ }^{24}$ If we exclude one outlier election discussed in Section 4.2, the test results for phase 3 are $U=3.087$ and $p \leq 0.024$.

${ }^{25}$ If we exclude the outlier election discussed in Section 4.2, we find significantly faster convergence also in AG12 $(U=1.586, p \leq 0.100)$.
} 


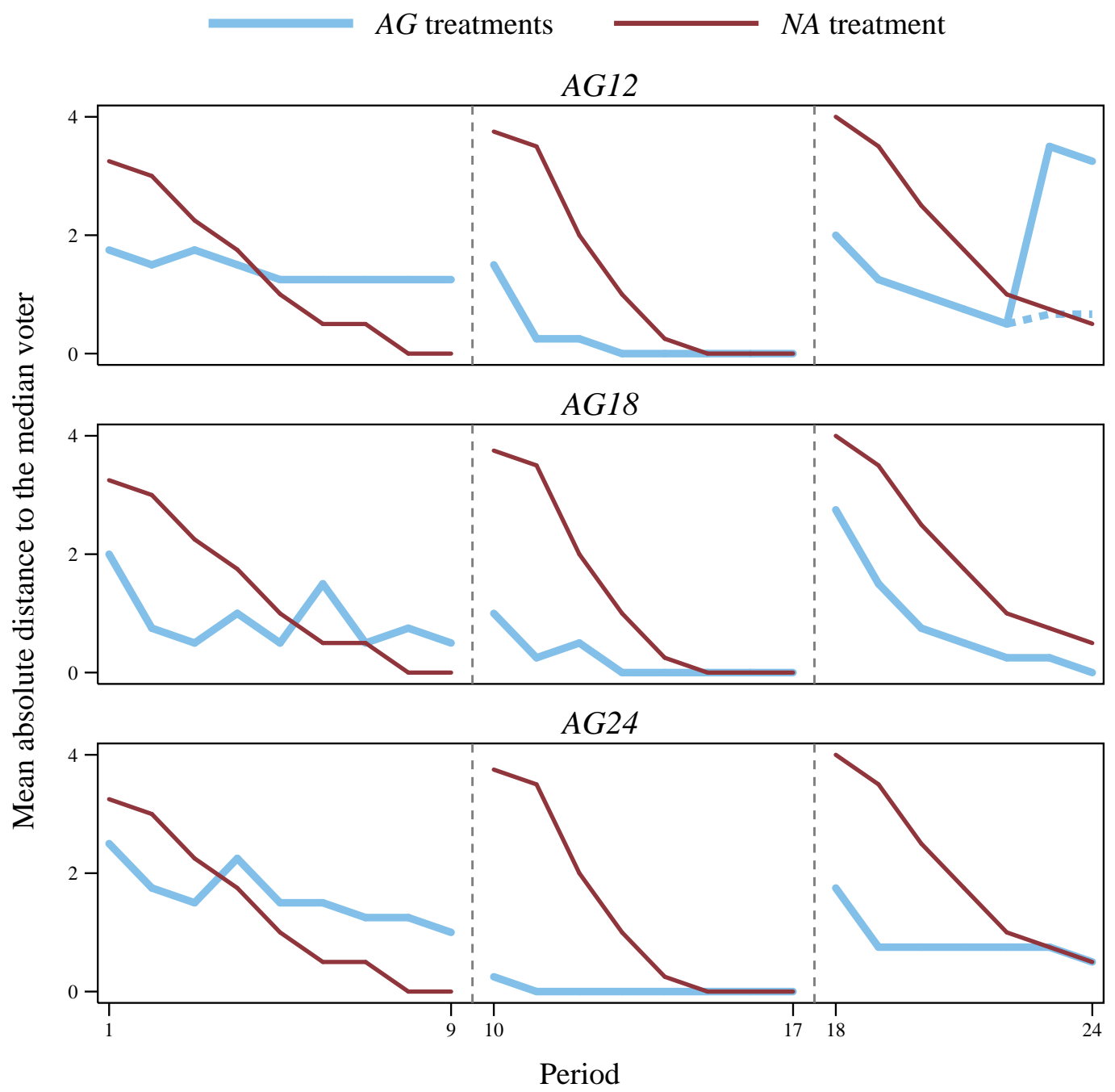

Figure 4: Mean distance between the location of the winning candidate and the location of the median voter. Thick blue lines correspond to the $A G$ treatments whereas thin red lines correspond to NA. The dotted line in AG12 corresponds to the mean distance excluding the outlier election (see Section 4.2).

occurred within three periods. The fastest case of convergence occurs in four periods. Hence, in $N A$ candidates adopt a strategy that is roughly consistent with the one-step strategy discussed above, whereas in the $A G$ treatments we observe behavior that is more akin to a multiple-step strategy. In fact, if we look at Table 1 we can see that in phases 2 and 3, convergence in AG18 and AG24 is faster than the mean convergence implied by the multiple-step strategy. This first set of findings is summarized in:

Result 1 In all treatments candidates converge to the location of the median voter. In NA, convergence is gradual as candidates tend to move one step at a time. In contrast, in AG treatments, candidates take multiple steps towards the median voter's location. This results in faster convergence, in particular, in the latter two phases. 


\section{$4.2 \quad$ Voting}

We now turn to the behavior that underlies these observations. Let us first consider voting. We find clear support for conjecture 1. In $N A, 97.26 \%$ of the votes are in line with sincere voting. Only $2.74 \%$ of the votes are cast for the candidate located further away from the respective voter. In the $A G$ treatments, sincere voting explains $93.97 \%$ of the votes in AG12, $94.24 \%$ in AG18, and $95.50 \%$ in AG24. If we test for statistical differences using session means as independent observations, we find significantly less sincere voting in the $A G$ treatments compared to $N A(U=4.222, p \leq 0.011)$. While this might be due to the increased complexity of the AG game, the rate of "correct" votes is still quite high relative to "error" rates of $20-30 \%$ that were observed in earlier experimental studies (e.g., McKelvey and Ordeshook, 1990a,b).

Result 2 The vast majority of votes are sincere, in the sense of voting for the candidate who is closer to a voter's preferred location.

Although very rare, "insincere" voting sometimes produced divergence from the location of the median voter - an observation, which is not specific to our experiment but commonly made in the literature (see Collier et al., 1987; McKelvey and Ordeshook, 1990a). Our data include 12 out of 384 elections $(3.13 \%)$ where the candidate further away from the median voter's location won the election. With one exception, this had only a small impact on convergence. In one session in $A G 12$, however, two subjects simultaneously voted for a candidate in a faraway location in the penultimate period. The result was a 12-location shift away from the location of the median voter (see session 1 in AG12, Figure C.1 in Appendix C). Since this election outcome was clearly an extreme outlier, we also report the effects when we exclude this election (and the subsequent period) from the data analysis.

\subsection{Formation of Advocacy Groups}

Our first result showed that the opportunity to form advocacy groups facilitates convergence. We now study the voters' actual decisions to form advocacy groups. Table 2 contains summary statistics for the mean number of advocacy groups formed per phase. Figure 5 depicts the formation of advocacy groups over periods and phases. Clearly, voters frequently form advocacy groups. On average, 29.00 groups are formed per session. Moreover, there seems to be a negative relationship between the cost of forming an advocacy group and the number of groups being formed: on average, 34.25 groups are formed in AG12, followed by 26.75 in AG18, and 26.00 in AG24. Thus, in line with conjecture 2 , we find strong evidence that voters form advocacy groups and that the number of groups declines as costs increase.

Figure 5 reveals that most advocacy groups are formed in the first period of each phase, particularly in phases 2 and 3. This behavior explains how candidates managed to converge so quickly to the median voter's location: there was plenty of information available already in the first period. However, from the point of view of information transmission, voters are forming 
Table 2: Mean number of advocacy groups distinguishing between groups that reveal new information in a phase and groups that do not. Standard deviations in parenthesis.

\begin{tabular}{|c|c|c|c|c|}
\hline & All $A G$ & AG12 & AG18 & $A G 24$ \\
\hline \multicolumn{5}{|l|}{ Overall } \\
\hline All advocacy groups & $29.00(9.27)$ & $34.25(12.07)$ & $26.75(4.35)$ & $26.00(9.76)$ \\
\hline Informative groups & $16.17(1.47)$ & $16.00(0.82)$ & & $15.75(1.71)$ \\
\hline Uninform & 12.83 & $18.25(11$ & & \\
\hline \multicolumn{5}{|l|}{ Phase 1} \\
\hline All advoc & $13.67(4.16)$ & $15.50 \quad(5.45)$ & $13.25(1.26)$ & $12.25(4.99)$ \\
\hline Infor: & & 6.25 & & $5.50(1.29)$ \\
\hline Uninform & & 9.25 & 6.75 & $6.75(4.11)$ \\
\hline \multicolumn{5}{|l|}{ Phase 2} \\
\hline & & $10.00(4.16)$ & & $7.50(3.11)$ \\
\hline & & 5.00 & & $.82)$ \\
\hline Uninf & 3.42 & 5.00 & 2.75 & 2.50 \\
\hline \multicolumn{5}{|l|}{ Phase 3} \\
\hline All advocacy & $6.92(2.84)$ & $8.75 \quad(3.86)$ & $5.75(0.96)$ & $6.25(2.63)$ \\
\hline Informativ & & $(0.50)$ & $5.25(0.96)$ & $5.25(0.96)$ \\
\hline Uninformative groups & $1.83(2.82)$ & $(3.92)$ & $0.50(0.58)$ & $1.00(2.00)$ \\
\hline
\end{tabular}

too many groups. After all, if an advocacy group is formed at each non-empty location in every phase, there would be 19 groups formed in a session ( 7 advocacy groups in phase 1 and 6 in both phases 2 and 3) -in the AG12 treatments we observe nearly twice as many groups on average. To further explore this excessive group formation behavior, we classify each advocacy group as being either informative or uninformative. Informative groups are those that, by forming, reveal new information to the candidates within a phase. Uninformative groups correspond to those that form at locations where a group had already formed within the same phase. In other words, they do not convey new information to the candidates. ${ }^{26}$

The mean number of informative and uninformative groups in each treatment can be seen in Table 2 and Figure 5 (in the figure uninformative groups are visualized as the difference between all groups and informative groups). In all treatments and phases, the number of informative groups is close to the maximum: overall, 6.08 out of 7 groups form in phase 1, 5.00 out of 6 groups in phase 2, and 5.08 out of 6 groups in phase 3. Moreover, as can be seen in Figure 5, informative groups are formed almost exclusively in the first couple of periods of each phase. Hence, the group formations almost completely revealed the distribution of voters early on in each phase of the experiment.

In addition to informative groups, voters frequently form uninformative groups. In total, uninformative groups account for nearly half of all advocacy groups (44.26\%). In AG12, where the formation of a group is relatively cheap, we observe the highest mean number of uninformative groups (18.25 groups). With higher costs, a smaller but still sizeable number of uninformative

\footnotetext{
${ }^{26}$ The terms informative and uninformative are more accurate from the perspective of voters, who know whether a new phase has started. By and large, candidates cannot distinguish between informative and uninformative groups because they do not know when preference shocks occur. Candidates only know that preference shocks do not occur in consecutive periods (see footnote 6). In this respect, uninformative groups could still convey useful information. For example, if interpreted as such, uninformative groups might be used to signal to the candidates that voter preferences have not changed.
} 

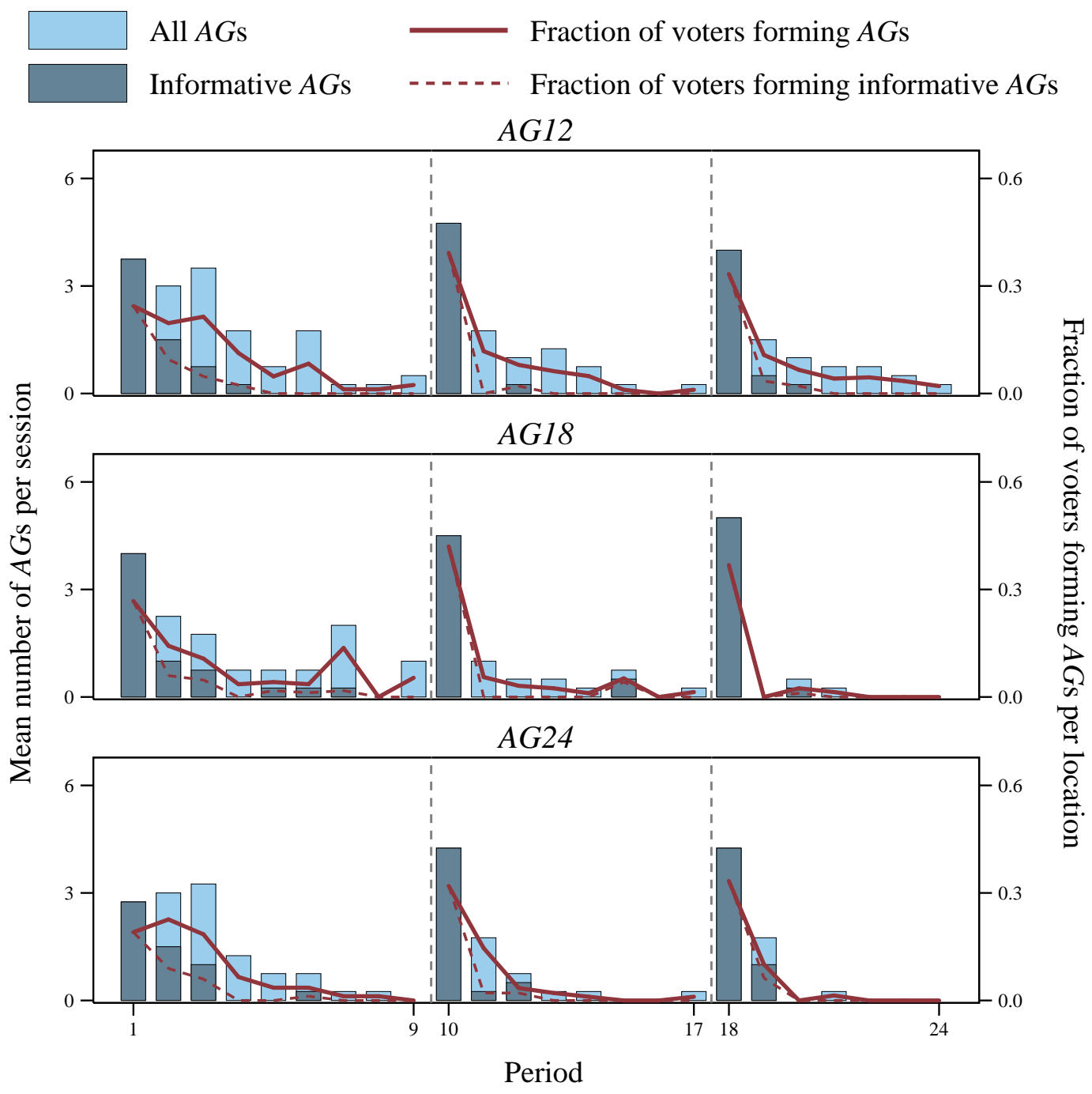

Figure 5: Mean number of advocacy groups formed per period distinguishing between all groups (light blue bars) and groups that reveal new information in a phase (dark blue bars), and mean fraction of voters per location who choose to form an advocacy group distinguishing between all groups (thick lines) and groups that reveal new information in a phase (dashed lines).

groups are formed: 10.00 groups in AG18 and 10.25 groups in AG24. As with informative groups, voters are less likely to form an uninformative group in the latter periods of a phase, although the decrease is not as pronounced as for informative groups. A clear difference between the two type of groups is also evident when we look at group formation across phases. Unlike informative groups, there is a clear tendency towards fewer uninformative groups in the later phases. An impression that is confirmed by the correlation between phase number and the amount of uninformative groups. In all treatments, the Spearman's rank-order correlation coefficient is negative, and for both AG18 and AG24, it is significantly different from zero (AG12: $\rho=-0.42$ and $p=0.176$; AG18: $\rho=-0.82$ and $p=0.001 ; A G 24: \rho=-0.66$ and $p=0.018)$. Hence, the formation of uninformative groups significantly declines with experience.

At the individual level, forming an advocacy group is a common decision, but it is far from universal. Over all three phases, $28.51 \%$ of voters never formed an advocacy group, $20.61 \%$ formed 
an advocacy group once, $19.74 \%$ formed an advocacy group twice, and only $31.14 \%$ formed an advocacy group three times or more. As a consequence, the cost of forming a given advocacy group is borne by a few voters in each location. This can seen in Figure 5, which displays the mean fraction of voters per location who choose to form an advocacy group over periods and phases. The figure reveals that in a given period, on average, at most half of the voters per location form an advocacy group. If we separate the decision by whether the group formed was informative or uninformative, we find that the cost of forming informative groups is borne by many more voters compared to the cost of forming uninformative groups. For instance, $64.04 \%$ of voters formed at least one informative advocacy group while only $35.53 \%$ of voters formed at least one uninformative advocacy group.

To study the voters' motivation to form advocacy groups in more detail, we conduct a regression analysis. As dependent variable we use a dummy that equals one if a voter $i$ chooses to form a group in period $t$ and zero otherwise. Our key independent variables are the number of voters in $i$ 's current location, the distance between $i$ 's location and the location of the incumbent, a dummy variable indicating whether the candidates have converged to the location of the median voter, the total cost of forming a group, the number of periods since the beginning of the current phase, and dummy variables indicating the phase number. Accounting for the panel structure of our data (recall that we observe 24 decisions for each voter), we estimate the effect of these variables on group formation choices using the random-effects Probit model. The estimated coefficients from the basic specification are presented in column (I) of Table 3.

The estimation results in column (I) support conjecture 2. First, the estimates indicate a negative coefficient for the cost of forming a group, although, it is not significant at conventional levels $(p=0.104)$. Second, voters are more likely to form a group the larger the distance between their location and the location of the incumbent. Third, groups are more likely to be formed in the early periods of each phase and group formation declines in the second and third phases. In addition to these findings, we also see that voters' propensity to form a group is significantly higher the larger the number of voters sharing a location. This suggests that-consistent with evidence from public goods games (e.g., Isaac et al., 1994) — voters at highly populated locations still manage to solve the collective action problem and effectively form more groups than voters at less populated locations. Specification (I) also shows that voters are significantly less likely to form a group once candidates have converged to the median voter's location, which is reassuring as it corroborates the voters' understanding of the game.

In column (II), we add the information obtained from the debriefing questionnaire as additional control variables. Specifically, we include dummies indicating female subjects, political orientation (equal to one for the $50 \%$ of subjects that lean most to the left), participation in political demonstrations (equal to one for the $50 \%$ of subjects that participate the most), and participation in elections (equal to one for the $50 \%$ of subjects that participate the most). ${ }^{27}$ Interestingly, the

\footnotetext{
${ }^{27}$ Three subjects failed to complete the debriefing questionnaire. Hence, the number of subjects drops from $N=228$ to $N=225$ in specifications (II), (IV) and (VI). See the note on Table 3.
} 
Table 3: Determinants of advocacy group formation (random-effects Probit)

\begin{tabular}{lcccccc}
\hline \hline & \multicolumn{2}{c}{ All $A G$} & \multicolumn{2}{c}{ Informative $A G$} & \multicolumn{2}{c}{ Uninformative $A G$} \\
& $(\mathrm{I})$ & $(\mathrm{II})$ & $(\mathrm{III})$ & $(\mathrm{IV})$ & $(\mathrm{V})$ & $(\mathrm{VI})$ \\
\hline Cost of $A G$ formation & -0.018 & $-0.019^{*}$ & -0.003 & -0.002 & $-0.027^{*}$ & $-0.029^{* *}$ \\
& $(0.011)$ & $(0.011)$ & $(0.010)$ & $(0.009)$ & $(0.015)$ & $(0.014)$ \\
\# voters at location & $0.176^{* * *}$ & $0.174^{* * *}$ & $0.182^{* *}$ & $0.183^{* * *}$ & -0.005 & -0.017 \\
& $(0.062)$ & $(0.063)$ & $(0.071)$ & $(0.071)$ & $(0.088)$ & $(0.088)$ \\
Distance to the incumbent & $0.075^{* * *}$ & $0.075^{* * *}$ & $0.121^{* * *}$ & $0.124^{* * *}$ & -0.001 & -0.005 \\
& $(0.015)$ & $(0.015)$ & $(0.021)$ & $(0.021)$ & $(0.020)$ & $(0.020)$ \\
Converged & $-0.581^{* * *}$ & $-0.579^{* * *}$ & $-0.646^{* * *}$ & $-0.628^{* * *}$ & -0.157 & -0.162 \\
& $(0.086)$ & $(0.087)$ & $(0.141)$ & $(0.141)$ & $(0.106)$ & $(0.106)$ \\
Periods since start of phase & $-0.259^{* * *}$ & $-0.263^{* * *}$ & $-0.568^{* * *}$ & $-0.579^{* * *}$ & $-0.074^{* * *}$ & $-0.077^{* * *}$ \\
& $(0.018)$ & $(0.018)$ & $(0.043)$ & $(0.045)$ & $(0.020)$ & $(0.020)$ \\
Phase 2 & $-0.147^{*}$ & $-0.140^{*}$ & 0.076 & 0.087 & $-0.410^{* * *}$ & $-0.402^{* * *}$ \\
& $(0.084)$ & $(0.085)$ & $(0.106)$ & $(0.107)$ & $(0.110)$ & $(0.110)$ \\
Phase 3 & $-0.536^{* * *}$ & $-0.538^{* * *}$ & $-0.211^{* *}$ & $-0.213^{* *}$ & $-0.788^{* * *}$ & $-0.776^{* * *}$ \\
& $(0.087)$ & $(0.088)$ & $(0.105)$ & $(0.106)$ & $(0.130)$ & $(0.131)$ \\
Female & & $-0.408^{* * *}$ & & $-0.399^{* * *}$ & & $-0.267^{*}$ \\
& & $(0.112)$ & & $(0.097)$ & & $(0.148)$ \\
Left leaning & & -0.169 & & -0.097 & & -0.183 \\
& & $(0.116)$ & & $(0.098)$ & & $(0.154)$ \\
Participated in demonstrations & & $0.368^{* * *}$ & & $0.280^{* * *}$ & & $0.371^{* *}$ \\
& & $(0.119)$ & & $(0.100)$ & & $(0.157)$ \\
Participated in elections & & 0.101 & & 0.085 & & 0.139 \\
& & $(0.108)$ & & $(0.091)$ & & $(0.143)$ \\
\hline Obs. $(N \times T)$ & 5472 & 5400 & 5472 & 5400 & 5472 & 5400 \\
\hline \hline
\end{tabular}

Note: The dependent variable equals one if voter $i$ forms an advocacy group in period $t$ and zero otherwise. I and II consider the formation of all advocacy groups, III and IV the formation of informative groups, and V and VI the formation of uninformative groups. $N=228$ in I, III, and V, and $N=225$ in II, IV, VI; $T=24$ periods. Standard errors in parentheses. ${ }^{* * *},{ }^{* *},{ }^{*}$ indicate statistical significance at the $1 \%, 5 \%$, and $10 \%$ level.

estimates reveal that subjects who most frequently participate in demonstrations are also more likely to form advocacy groups. In contrast, we do not see this effect for participation in elections. This finding suggests that subjects might be motivated to form advocacy groups by a specific desire to make themselves heard, but it is not part of a more general desire for political participation (Brennan and Lomasky, 1997). We also find that, compared to men, women are less likely to form groups. Comparing columns (I) and (II) also shows that the inclusion of the additional controls has a very small effect on the estimates from the baseline specification. The only difference is that the effect of the costs of group formation is now significant at the $10 \%$ level.

To account for potential differences in the motivation behind the formation of informative and uninformative groups, we run additional regressions with the same specification as in columns (I) and (II) but distinguish between these two types of groups. Columns (III) and (IV) report estimates that use a dummy indicating whether voter $i$ forms an informative group in period $t$ as the dependent variable. The results are quite similar to the ones from columns (I) and (II). The most noticeable difference is that the coefficient for the group formation cost is considerably smaller and no longer significant. In other words, the creation of informative advocacy groups 
does not seem to depend on the cost of forming groups - at least for the range of costs considered in our treatments.

Columns (V) and (VI) display the estimates where the dependent variable is a dummy indicating whether voter $i$ forms an uninformative group. These last two specifications point to substantial differences in the motives underlying the formation of uninformative versus informative groups. In particular, the formation of uninformative advocacy groups is neither driven by the number of voters in a location or the distance to the incumbent, nor by whether candidates have already converged to the median voter's location. Thus, in contrast to informative groups, the formation of uninformative groups is not driven by most variables measuring the amount of transmitted information, which is consistent with the fact that uninformative groups do not transmit new information to the candidates. By contrast, for uninformative groups the cost of group formation has a significantly negative effect, indicating that the formation of uninformative groups is more cost sensitive. Moreover, mirroring the decline across phases seen in Table 2, the estimations display a substantial negative effect on the formation of uninformative groups in phases 2 and 3. One might argue that, as voters acquire experience, they learn that uninformative groups are ineffective and thus form fewer uninformative groups. However, the fact that we observe uninformative groups also in the last phase of AG12, where group formation costs are low, might be interpreted in terms of some voters' desire to simply express their preferences (Brennan and Buchanan, 1984; Brennan and Lomasky, 1997).

Result 3 Voters make frequent use of the opportunity to form advocacy groups. Two different types of groups are formed: informative groups, which transmit new information, and uninformative groups, which provide no new information. The determinants for forming these groups differ. Before convergence, subjects in locations with many other voters and in locations with a larger distance to the incumbent are more likely to form informative groups. In contrast, the formation of uninformative groups is independent of these characteristics but is relatively more sensitive to costs.

In a next step, we move beyond the analysis of the objective descriptors of voters' situations and examine the impact of voters' subjective beliefs. Recall that we elicit proxies for the subjects' beliefs concerning the costs and benefits of forming an advocacy group in seven periods (1-3, 1011, and 18-19). To capture the benefits from a group, we asked each voter to indicate the expected location of the winning candidate for two situations: when a group forms in the voter's location and when a group does not form in that location. The difference between these expected locations gives us a proxy of the voter's expected benefit of forming an advocacy group. To measure beliefs regarding the costs of a group formation, voters are asked to indicate the expected number of other voters at their location who will choose to form a group. Since the total costs of a group are shared with these voters, this expectation determines the voters' expected cost. ${ }^{28}$

\footnotetext{
${ }^{28}$ On average, subjects believe that 0.73 other voters will form a group in their location. The mean belief is largest in $A G 12$ (0.78), followed by AG18 (0.75), and AG24 (0.67).
} 
Table 4: Determinants of advocacy group formation and voters' beliefs (random-effects Probit)

\begin{tabular}{lcccc}
\hline \hline & $(\mathrm{I})$ & $(\mathrm{II})$ & $(\mathrm{III})$ & $(\mathrm{IV})$ \\
\hline Expected \# voters forming an $A G$ & & $2.323^{* * *}$ & & $2.398^{* * *}$ \\
& & $(0.150)$ & & $(0.164)$ \\
Expected gain from forming an $A G$ & & & $0.226^{* * *}$ & $0.242^{* * *}$ \\
& & & $(0.023)$ & $(0.027)$ \\
Cost of $A G$ formation & -0.009 & 0.004 & -0.008 & 0.005 \\
& $(0.013)$ & $(0.014)$ & $(0.013)$ & $(0.015)$ \\
\# voters at location & $0.194^{* *}$ & $0.173^{*}$ & $0.258^{* * *}$ & $0.242^{* *}$ \\
& $(0.077)$ & $(0.091)$ & $(0.080)$ & $(0.096)$ \\
Distance to the incumbent & $0.085^{* * *}$ & $0.080^{* * *}$ & $0.084^{* * *}$ & $0.077^{* * *}$ \\
& $(0.021)$ & $(0.022)$ & $(0.022)$ & $(0.026)$ \\
Converged & $-0.461^{* * *}$ & $-0.389^{* *}$ & $-0.451^{* * *}$ & $-0.380^{* *}$ \\
& $(0.142)$ & $(0.169)$ & $(0.145)$ & $(0.174)$ \\
Periods since start of phase & $-0.410^{* * *}$ & $-0.223^{* * *}$ & $-0.344^{* * *}$ & $-0.167^{* *}$ \\
& $(0.068)$ & $(0.081)$ & $(0.070)$ & $(0.085)$ \\
Phase 2 & -0.058 & -0.050 & 0.060 & 0.048 \\
& $(0.111)$ & $(0.132)$ & $(0.116)$ & $(0.140)$ \\
Phase 3 & $-0.339^{* * *}$ & $-0.273^{* *}$ & $-0.230^{*}$ & -0.168 \\
& $(0.113)$ & $(0.133)$ & $(0.118)$ & $(0.141)$ \\
Female & $-0.510^{* * *}$ & $-0.452^{* * *}$ & $-0.556^{* * *}$ & $-0.533^{* * *}$ \\
& $(0.129)$ & $(0.145)$ & $(0.132)$ & $(0.154)$ \\
Left leaning & -0.123 & -0.113 & -0.124 & -0.114 \\
& $(0.133)$ & $(0.150)$ & $(0.135)$ & $(0.157)$ \\
Participated in demonstrations & $0.390^{* * *}$ & $0.262^{*}$ & $0.351^{* *}$ & 0.217 \\
& $(0.139)$ & $(0.152)$ & $(0.139)$ & $(0.160)$ \\
Participated in elections & 0.092 & 0.096 & 0.071 & 0.099 \\
& $(0.126)$ & $(0.139)$ & $(0.128)$ & $(0.146)$ \\
\hline Obs. $(N \times T)$ & 1575 & 1575 & 1575 & 1575 \\
\hline \hline
\end{tabular}

Note: The dependent variable equals one if voter $i$ forms an advocacy group in period $t$ and zero otherwise. $N=225$ voters, $T=7$ periods. Standard errors in parentheses. ${ }^{* * *},{ }^{* *},{ }^{*}$ indicate statistical significance at the $1 \%, 5 \%$, and $10 \%$ level.

Table 4 presents the regressions analyzing the effect of the voters' beliefs. ${ }^{29}$ We first replicate specification (II) from Table 3 using the restricted sample of periods for which we collected data on beliefs. As can be seen in column (I) of Table 4, the results are qualitatively similar to the ones obtained with the full sample. Specifications (II) to (IV) gradually introduce the data on the voters' beliefs. We find positive and statistically significant coefficients for both the expected gain (in locations) of forming an advocacy group and the expected number of other voters forming a group. It is reassuring to see that, as one would expect, the more the voters think they will attract the challenger by forming a group, the more likely they are to form one. What is more surprising is the positive effect of the expected number of other voters on forming a group.

If voters maximize solely their monetary payoff, we should get a negative coefficient for this variable because the fact that others are forming a group allows voters to enjoy the gains of the advocacy group without having to pay its cost. However, instead of free-riding on the efforts of others, it appears that voters have a preference to conditionally cooperate when forming advocacy

\footnotetext{
${ }^{29}$ Note that we do not distinguish between informative and uninformative groups. The reason is that we elicited beliefs in early periods in each phase. During these periods, basically all groups are informative.
} 
groups. In other words, the more other voters are expected to join in the collective effort to form a group, the more likely a voter will participate in the formation herself. ${ }^{30}$ This finding provides suggestive evidence on conditionally cooperative voters and parallels results from public good experiments (Keser and van Winden, 2000; Fischbacher et al., 2001; Fischbacher and Gächter, 2010).

When we control for the voters' beliefs, the dummy for phase 3 as well as the variable indicating frequent participation in political demonstrations lose statistical significance in specification (IV). This observation indicates that the decline in group formation in the third phase of the experiment is driven by changes in beliefs concerning the costs and benefits from forming a group, which is in line with voters' learning during the course of the experiment. This point is also reflected in the descriptive statistics. In the first phase of the experiment, voters expect the winning candidate to be 0.92 steps closer to their location if a group is formed there. In the second (third) phase, the corresponding number is 0.33 (0.32) steps. Hence, in later phases of the game, voters expect that advocacy groups have a significantly smaller impact on the location choice $(U=3.687$, $p \leq 0.001$ and $U=3.834, p \leq 0.001$ when comparing phase 1 with phases 2 and 3 respectively). The results further indicate that subjects who frequently participate in political demonstrations are significantly more optimistic, regarding the others' inclination to form advocacy groups: those who frequently joined political demonstrations expect on average 0.89 other voters to form a group, whereas subjects who do not participate as often only expect 0.68 other voters to form a group. The difference is statistically significant $(p \leq 0.010)$.

Result 4 In line with rational decision-making, voters' expected benefits from an advocacy group and their willingness to form a group are positively correlated. However, the positive correlation between expectations about other voters forming a group and their own decision conflicts with the idea of free-riding: voters are more likely to form an advocacy group, the more others are expected to engage in the group formation.

Let us briefly recap the findings from this subsection. Our analysis of the advocacy group formation shows that voters form informative advocacy groups in situations where they are likely to gain from the information transmission to the candidates. Informative groups are formed in early periods within a phase, in locations that are far from the incumbent and when they expect to attract the winning candidate. Interestingly, voters seem to behave conditionally cooperativethey are more likely to invest into the collective action of forming a group if they expect others will do so as well.

Our results also indicate that the formation of uninformative groups is driven by quite different motives. In particular, uninformative groups are most likely to be formed in the first phase of the experiment-when voters have still little experience with the game. Moreover, uninformative groups appear more often when the costs to form them are relatively low. This result can be

\footnotetext{
${ }^{30}$ Admittedly, our finding could also be driven by cognitive dissonance. In other words, voters who form a group might be rationalizing their behavior ex-post by indicating that they expect others will do the same.
} 
explained with models of noisy decision making if we think of uninformative groups as mistakes. In this case, the effect of the cost of group formation is explained by assuming that mistakes are more likely when they are less costly. In line with this interpretation, the decline of uninformative groups in the later phases can be seen as a learning effect. A similar interpretation is that voters attempt to trick the candidates into thinking that a new phase has started by forming a group, but they learn that this strategy is ineffective, either because a candidate has already converged to the median voter's location or because candidates anticipate this type of attempts. Finally, one could also interpret our results as evidence of an affective response that gives voters pleasure from displaying their presence - similar to expressive voting (e.g., Tyran, 2004; Feddersen et al., 2009) — and is evaluated against the cost of doing so (Brennan and Buchanan, 1984; Brennan and Lomasky, 1997). The latter interpretation is more consistent with the fact that the formation of uninformative groups is not affected by other variables such as the candidates having converged to the median voter's location or the distance between the voter and the incumbent.

\subsection{Candidates}

We now come to the candidates' behavior. In particular, we are interested in analyzing how the speed at which candidates move towards the median voter's location is related to the (i) information revealed through voting and (ii) the formation of advocacy groups. To capture the speed at which challengers move towards the location of the median voter, we construct a variable that counts the number of locations that a challenger moves in the direction of the median voter (taking the location of the incumbent as the starting point). In other words, in each period we look at the absolute distance between the location chosen by the challenger and the location of the incumbent. If the challenger moves towards the median voter's location, we consider this distance to be positive and otherwise it is negative. ${ }^{31}$

The first explanatory variable, the vote margin, is a measure of the additional information contained in the election's vote tally (i.e., in addition to the information revealed by the fact that a specific candidate won/lost the election). It equals the number of votes by which the current incumbent won the previous election. To account for the few cases of divergence (see Section 4.2) we code this number as positive if the winner was the candidate closest to the median voter's location and negative if the winner was the candidate furthest away. Thus, the variable captures the strength of the information contained in the electoral result as well as whether this information points candidates towards the location of the median voter.

The second explanatory variable, the informative AG margin, measures the information revealed by advocacy groups. Specifically, it equals the total number of voters in a phase who have been revealed to the left (right) minus the number of voters revealed to the right (left) of the cur-

\footnotetext{
${ }^{31}$ This approach is justifiable as there are hardly any cases in which challengers overshoot the median voter's location. Using a similar dependent variable where we use the absolute improvement towards the median voter's location relative to the location of the incumbent yields very similar results. However, it is substantially more complicated to interpret the coefficients for this alternative dependent variable.
} 
Table 5: Determinants of the challenger's location choice (OLS estimates)

\begin{tabular}{|c|c|c|c|c|}
\hline & (I) & (II) & (III) & (IV) \\
\hline & \multicolumn{2}{|c|}{ All treatments } & \multicolumn{2}{|c|}{$A G$ treatments } \\
\hline \multirow[t]{2}{*}{ Vote margin } & $0.116^{* * *}$ & $0.126^{* * *}$ & $0.094^{*}$ & $0.095^{*}$ \\
\hline & $(0.037)$ & $(0.046)$ & $(0.050)$ & $(0.051)$ \\
\hline \multirow[t]{2}{*}{$N A$} & $-2.655^{* *}$ & $-2.597^{* *}$ & & \\
\hline & $(1.125)$ & $(1.158)$ & & \\
\hline \multirow[t]{2}{*}{ Vote margin $\times N A$} & & -0.030 & & \\
\hline & & $(0.062)$ & & \\
\hline \multirow[t]{2}{*}{ Informative $A G$ margin } & & & $0.219^{* * *}$ & $0.204^{* * *}$ \\
\hline & & & $(0.053)$ & $(0.076)$ \\
\hline \multirow[t]{2}{*}{ Total $A G$ margin } & & & & 0.014 \\
\hline & & & & $(0.038)$ \\
\hline Obs. & 191 & 191 & 125 & 125 \\
\hline
\end{tabular}

Note: The dependent variable is the number of locations the challenger moves in the direction of the median voter's location in period $t$. Regressions include period and session dummies (not reported). Robust standard errors in parentheses. ${ }^{* * *},{ }^{* *},{ }^{*}$ indicate statistical significance at the $1 \%, 5 \%$, and $10 \%$ level.

rent incumbent, given that in the current period the median voter is located to the left (right). ${ }^{32}$ Paralleling the vote margin, this variable measures the strength of the information revealed by advocacy groups and whether this information points candidates towards the median voter's location. Our third explanatory variable, the total AG margin, is constructed in the same way as the informative $A G$ margin except that, instead of counting revealed voters at most once during a phase, it continues to count these voters every time an advocacy group is formed (within a phase). This variable allows us to test whether the formation of uninformative groups has an effect on the candidates' behavior.

We regress the movement of the challenger on these measures for the different sources of information using OLS. All estimates include a full set of period fixed effects as well as session dummies. Moreover, we only use periods before candidates converge to the median voter's location. The results are presented in Table 5. Specification (I), which is based on data from all treatments, includes the vote margin and a dummy for the $N A$ treatment as regressors. The estimates show a significantly positive coefficient for the vote margin, indicating that challengers do use the information contained in the vote tally when making their location choice: a stronger voting result makes challengers take larger steps. At the same time, the coefficient for $N A$ is significantly negative. This captures the fact that challengers in the NA treatment take - for a given vote margin - steps which are on average 2.6 locations smaller towards the median voter (see Section 4.1). In column (II), we add an interaction term between the vote margin and the NA treatment dummy. The coefficient of the interaction term is not significantly different from zero, suggesting that the in-

\footnotetext{
${ }^{32} \mathrm{~A}$ revealed voter is a voter whose location is known because at least one advocacy group has been formed at her location in the current phase. Consider an example which is based on the voter distribution from phase 2, displayed in Figure 1: if the incumbent is positioned at $\ell_{t}^{I}=5$ and the median voter is at location 7 , then the informative $A G$ margin equals -1 if the three voters at location 3 are revealed in period $t$ and the two voters at location 12 were revealed in period $t-1$.
} 
formation contained in the vote tally is equally useful (in terms of convergence) to candidates in both treatments.

In columns (III) and (IV), we restrict our focus to the $A G$ treatments, and we evaluate the effect of the information revealed by advocacy groups. Specification (III) includes the informative $A G$ margin along with the vote margin. The estimates yield a positive and statistically significant coefficient for both variables. ${ }^{33}$ This indicates that candidates use both, the information revealed by advocacy groups and the information contained in the vote tally. Hence, it appears that the information from elections and the information transmitted by advocacy groups are complementary in shaping the challengers' location choices. Quantitatively, however, the AG margin has twice the impact of the vote margin. Finally, column (IV) includes the total AG margin. The estimates show that the additional variable is economically and statistically insignificant and has hardly any effect on the point estimates for the other coefficients. Since the total AG margin captures the potential effect of uninformative advocacy groups, we can conclude that challengers ignore these groups when deciding where to locate. Hence, they do understand that uninformative advocacy groups convey no new information.

Result 5 In their movement towards the median voter's location, candidates rely on information contained in the electoral outcome and the information revealed by the advocacy groups. Candidates respond to informative advocacy groups but not to uninformative advocacy groups.

This result, combined with the behavior of voters (see Section 4.3) explains the faster convergence to the median voter's location in the $A G$ treatments. Lastly, the fact that candidates ignore uninformative advocacy groups confirms that their formation is a waste of resources - at least in terms of monetary payoffs - which explains why we see a decline in the number of uninformative groups over phases (see Section 4.3).

\subsection{Payoffs}

The results discussed above establish that voters do form advocacy groups and that, by doing so, they speed up convergence to the median voter's location. We now study to which extent the payoff gains from quicker convergence offset the costs of forming advocacy groups. A look at the mean payoff of voters suggests that payoff gains and group-formation costs cancel each other out. Voters in the $N A$ treatment earn on average 49.32 points per period. In contrast, voters in the AG12, AG18, and AG24 treatments earn on average 48.78, 49.14, and 48.67 points, respectively. Compared to NA, payoffs are significantly lower in AG12 and AG24 ( $p \leq 0.057$ and $p \leq 0.014)$ and are not significantly different in $A G 18(U=0.834)$. Hence, the data reject conjecture 4 (for $A G 12$ and $A G 24)$ : the $A G$ treatments fail to yield an overall payoff increase.

Figure 6 provides a more detailed look at the payoffs. For each phase, the figure depicts the mean payoff gains (losses) due to faster (slower) convergence in each $A G$ treatment compared to

\footnotetext{
${ }^{33}$ The standard error of the coefficient for the vote margin increases because of the smaller sample size and the fairly high correlation between the vote margin and the informative $A G$ margin.
} 


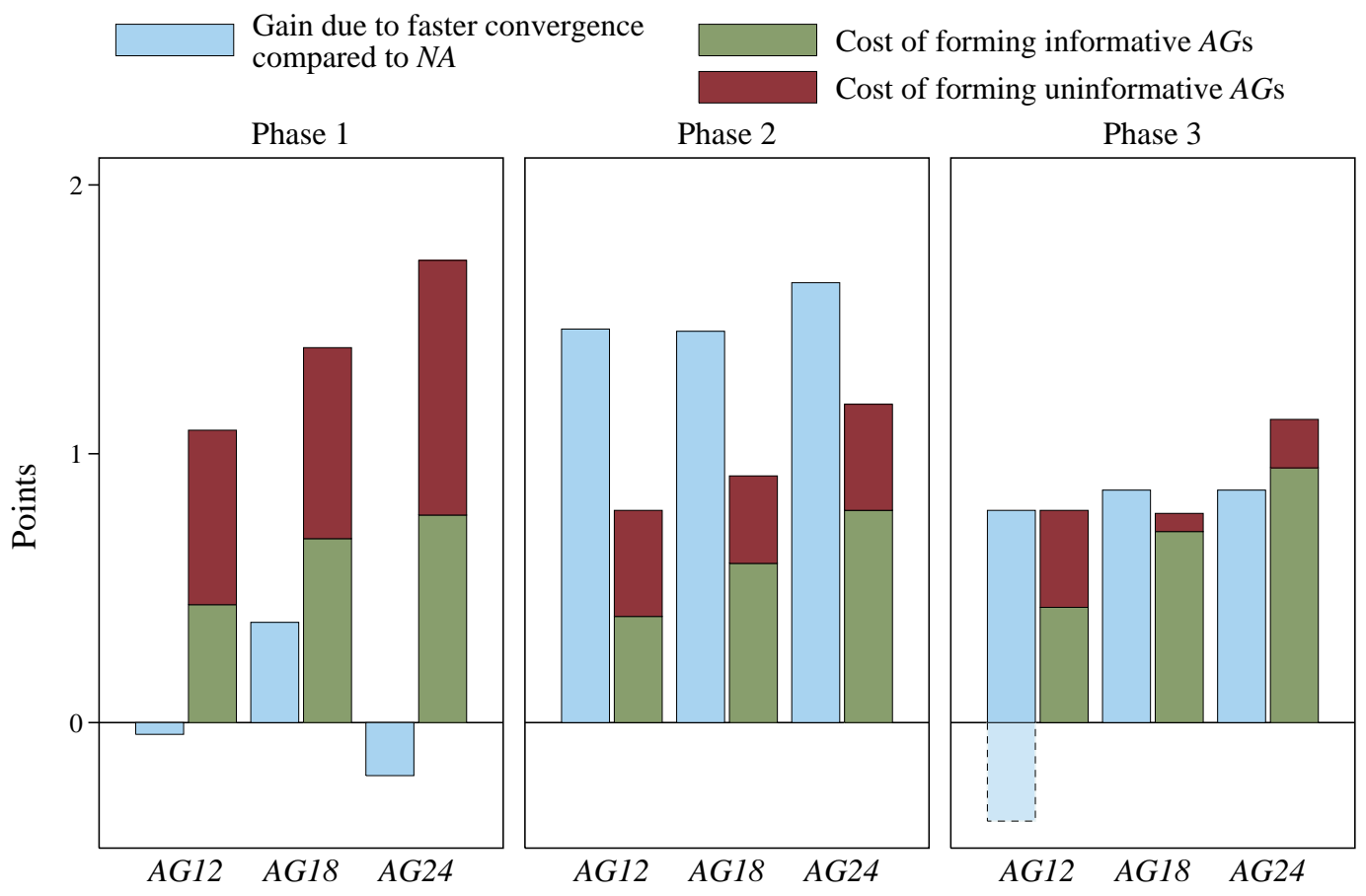

Figure 6: Mean voter payoff in each $A G$ treatment excluding group formation costs minus the mean voter payoff in the NA treatment (light blue bars) and (mean cost per voter of forming of advocacy groups depending on whether the group was informative or uninformative. The area marked by the dashed line corresponds to the payoff difference caused by the outlier election discussed in Section 4.2 .

the NA treatment-i.e., the mean payoff in an $A G$ treatment excluding group formation costs minus the mean payoff in the $N A$ treatment. In addition, the figure displays the mean cost of forming informative as well as uninformative groups, respectively.

Figure 6 clearly indicates that, in phase 1, the $A G$ treatments yield on average lower payoffs than the $N A$ treatment. Voters in $A G$ treatments do not benefit from faster convergence during this phase. At the same time, they incur considerable costs from the formation of informative and uninformative advocacy groups. The payoffs in this phase are therefore significantly lower in each $A G$ treatment compared to $N A(U \geq 3.364, p \leq 0.057)$.

Phase 2 shows a considerable improvement in the relative payoffs in the $A G$ treatments: convergence speeds up and the number of advocacy groups decreases. In all $A G$ treatments, the gains of faster convergence exceed the costs of forming advocacy groups. In AG18 this results in significantly higher payoffs compared to $N A(U=2.502, p=0.057)$. In AG12 and AG24 the difference is not statistically significant $(U=1.775, p \leq 0.100$, and $U=0.834, p>0.100$ respectively). For phase 3 , we get once again inconclusive results. Correcting for the outlier election in AG12 (see Section 4.2), we observe that all $A G$ treatments do better than $N A$ in terms of convergence. However, the payoff advantage from faster convergence is small and thus canceled out by the costs 
of advocacy groups. We do not find a significant difference in payoffs between $N A$ and any of the $A G$ treatments $(U \leq 0.384) .{ }^{34}$

Result 6 The opportunity to form advocacy groups does not yield higher monetary payoffs to the voters: on average, the payoff gains from faster convergence are offset by the costs of forming advocacy groups.

While advocacy groups do not have a positive effect on average payoffs, one might argue that quicker convergence on one hand and the option of forming a group on the other constitute a positive welfare effect beyond payoffs. Advocacy groups give voters an additional channel to make themselves heard and to express their preferences. This case is supported by some of the evidence from Section 4.3, which points towards expressive motives in the formation of uninformative groups. If these groups are not the result of mistakes but of preference-revealing acts, then uninformative groups do contribute to welfare. Hence, accounting for the non-payoff-instrumental welfare effects that are implicit in groups, the $A G$ treatments could outperform the $N A$ treatment.

\section{Conclusions}

This paper studies the formation of advocacy groups and their role in transmitting information in a laboratory experiment. Within a spatial electoral competition setting, we find that voters make frequent use of the costly opportunity to form advocacy groups and reveal information to candidates. This additional information accelerates convergence to the median voter equilibrium, especially after major preference shocks where the endogenous creation of advocacy facilitates the transition to the new equilibrium.

One contribution of our paper is documenting several interesting patterns in the formation of advocacy groups. First, the more voters share a political preference, the more likely they are to form an advocacy group. In other words, rather than struggling with an aggravated freerider/coordination problem, larger groups of voters are more active in collective action. Second, voters behave as conditional cooperators: namely, they are more likely to engage in the collective action of forming an advocacy group if they expect others will do so as well. It is worth noting that both of these patterns closely resemble evidence from public goods experiments. Third, voters with preferences that strongly differ from the incumbent's location are more active in forming advocacy groups. This observation is consistent with the view that individuals who think that their opinions are not being represented in the political process are willing to organize in order to express their voice. Fourth, and consistent with this idea of an expressive motive, we observe the formation of informative as well as uninformative advocacy groups. Some of the evidence suggests that these

\footnotetext{
${ }^{34}$ If we exclude the costs of forming uninformative groups, we find that all $A G$ treatments have significantly higher payoffs compared to $N A$ in phase 2 ( $p \leq 0.014$ in all cases). Thus, if voters had restricted themselves to forming only informative groups, the payoff gains from faster convergence would have exceeded the costs of forming advocacy groups (assuming that, as suggested by Result 4, convergence is unaffected by lack of uninformative advocacy groups). In contrast, excluding the costs of uninformative groups in phase 3 is not enough to deliver a payoff gain in the $A G$ treatments $(U \leq 1.027)$.
} 
latter groups, which do not reveal any new information, are at least partly triggered by a motive of "expressive advocacy".

All these patterns might be used to guide theories of how voters transmit information to candidates. Further exploring the robustness of our findings is a promising avenue for further research. In this respect, we think it is particularly promising to study more the possible expressive dimension of political collective action. In addition, it would be interesting to investigate the effects of weakening some of our stronger assumptions. For example, by running an experiment where voters only know a fraction of the other voters in their location or where forming an advocacy group reveals only some of the voters with a particular policy preference.

Finally, from the perspective of optimal democratic governance, it is important to stress that the costs of advocacy had no significant effect on the formation of informative groups but reduced the frequency at which uninformative groups emerged. Hence, decreasing advocacy costs had neither a beneficial effect on the intensity of preference revelation nor on the speed of convergence. This last finding suggests that - in a democratic society with non-inhibitive costs of collective action - the spread of new communication technologies and the corresponding decline in the costs of organizing might only increase the frequency of expressive but not necessarily informative advocacy. In less developed democracies, however, the same technological innovations might allow for an important step towards more information transmission and better governance. It is up for future research to confront these implications with field data.

\section{References}

Battaglini, M., Morton, R. B., and Palfrey, T. R. (2009). The swing voter's curse in the laboratory. Review of Economic Studies, 77(1):61-89.

Blanco, M., Engelmann, D., Koch, A. K., and Normann, H.-T. (2010). Belief elicitation in experiments: Is there a hedging problem? Experimental Economics, 13(4):412-438.

Brennan, G. and Buchanan, J. (1984). Voter choice: Evaluating political alternatives. American Behavioral Scientist, 28(2):185-201.

Brennan, G. and Lomasky, L. E. (1997). Democracy and decision: The pure theory of electoral preference. Cambridge University Press, New York.

Camerer, C. F. (2003). Behavioral game theory: Experiments in strategic interaction. Princeton University Press, New Jersey.

Chaudhuri, A. (2010). Sustaining cooperation in laboratory public goods experiments: a selective survey of the literature. Experimental Economics, 14(1):47-83.

Cherry, T. L., Cotten, S. J., and Kroll, S. (2013). Heterogeneity, coordination and the provision of best-shot public goods. Experimental Economics, 16(4):497-510.

Collier, K. E., McKelvey, R. D., Ordeshook, P. C., and Williams, K. C. (1987). Retrospective voting: An experimental study. Public Choice, 53(2):101-130.

Crawford, V. P. and Sobel, J. (1982). Strategic information transmission. Econometrica, $50(6): 1431$. 
Downs, A. (1957). An economic theory of democracy. Harper and Brothers, New York.

Feddersen, T., Gailmard, S., and Sandroni, A. (2009). Moral bias in large elections: Theory and experimental evidence. American Political Science Review, 103(02):175.

Fischbacher, U. and Gächter, S. (2010). Social preferences, beliefs, and the dynamics of free riding in public goods experiments. American Economic Review, 100(1):541-556.

Fischbacher, U., Gächter, S., and Fehr, E. (2001). Are people conditionally cooperative? evidence from a public goods experiment. Economics Letters, 71(3):397-404.

Fligner, M. A. and Policello, G. E. (1981). Robust rank procedures for the Behrens-Fisher problem. Journal of the American Statistical Association, 76(373):162.

Friedman, D. and Massaro, D. W. (1998). Understanding variability in binary and continuous choice. Psychonomic Bulletin \& Review, 5(3):370-389.

Gächter, S. and Renner, E. (2010). The effects of (incentivized) belief elicitation in public goods experiments. Discussion Paper 2006-16 3, CeDeX.

Gneezy, U. (2005). Deception: The role of consequences. American Economic Review, 95(1):384394.

Großer, J. and Schram, A. (2010). Public opinion polls, voter turnout, and welfare: An experimental study. American Journal of Political Science, 54(3):700-717.

Grossman, G. M. and Helpman, E. (2001). Special interest politics. MIT Press, Boston.

Hamby, P. (2013). Did twitter kill the boys on the bus? searching for a better way to cover a campaign. Discussion paper no. D-80, Joan Shorenstein Center, Harvard University.

Hao, L. and Houser, D. (2013). Perceptions, intentions, and cheating. Working paper, George Mason University.

Isaac, R., Walker, J. M., and Williams, A. W. (1994). Group size and the voluntary provision of public goods. Journal of Public Economics, 54(1):1-36.

Jiang, T. (2013). Cheating in mind games: The subtlety of rules matters. Journal of Economic Behavior \& Organization, 93:328-336.

Keck, M. E. and Sikkink, K. (1998). Activists beyond borders: Advocacy networks in international politics, volume 35. Cornell University Press, Ithaca.

Keser, C. and van Winden, F. (2000). Conditional cooperation and voluntary contributions to public goods. Scandinavian Journal of Economics, 102(1):23-39.

Kroll, S., Cherry, T. L., and Shogren, J. F. (2007). The impact of endowment heterogeneity and origin on contributions in best-shot public good games. Experimental Economics, 10(4):411-428.

Levine, D. K. and Palfrey, T. R. (2007). The paradox of voter participation? a laboratory study. American Political Science Review, 101(1):143-158.

McKelvey, R. D. and Ordeshook, P. C. (1984). Rational expectations in elections: Some experimental results based on a multidimensional model. Public Choice, 44(1):61-102.

McKelvey, R. D. and Ordeshook, P. C. (1985a). Elections with limited information: A fulfilled expectations model using contemporaneous poll and endorsement data as information sources. Journal of Economic Theory, 36(1):55-85. 
McKelvey, R. D. and Ordeshook, P. C. (1985b). Sequential elections with limited information. American Journal of Political Science, 29(3):480.

McKelvey, R. D. and Ordeshook, P. C. (1990a). A decade of experimental research on spatial models of elections and committees. In Hinich, M. J. and Enelow, J., editors, Advances in the Spatial Theory of Voting. Cambridge University Press, Cambridge.

McKelvey, R. D. and Ordeshook, P. C. (1990b). Information and elections: Retrospective voting and rational expectations. In Ferejohn, J. and Kuklinski, J., editors, Information and Democratic Precesses. University of Illinois Press, Urbana Champaign.

Morton, R. B. and Tyran, J.-R. (2011). Let the experts decide? asymmetric information, abstention, and coordination in standing committees. Games and Economic Behavior, 72(2):485-509.

Mueller, D. C. (2003). Public Choice III. Cambridge University Press, Cambridge.

Obar, J. A., Zube, P., and Lampe, C. (2012). Advocacy 2.0: An analysis of how advocacy groups in the united states perceive and use social media as tools for facilitating civic engagement and collective action. Journal of Information Policy, 2:1-25.

Palfrey, T. R. (2013). Experiments in political economy. In Kagel, J. H. and Roth, A. E., editors, Handbook of Experimental Economics 2. Princeton University Press, Princeton.

Persson, T. and Tabellini, G. E. (2002). Political economics: Explaining economic policy. MIT Press, Boston.

Richardson, J. J. (1993). Introduction: Pressure groups and government. In Richardson, J., editor, Pressure Groups. Oxford University Press, New York.

Sadiraj, V., Tuinstra, J., and van Winden, F. (2006). A computational electoral competition model with social clustering and endogenous interest groups as information brokers. Public Choice, 129(1-2):169-187.

Sánchez-Pagés, S. and Vorsatz, M. (2007). An experimental study of truth-telling in a senderreceiver game. Games and Economic Behavior, 61(1):86-112.

Sánchez-Pagés, S. and Vorsatz, M. (2008). Enjoy the silence: an experiment on truth-telling. Experimental Economics, 12(2):220-241.

Sheremeta, R. M. (2011). Perfect-substitutes, best-shot, and weakest-link contests between groups. Korean Economic Review, 27:5-32.

Sinclair, B. and Plott, C. (2012). Informing the uninformed: Do voters learn from pre-election polls? Electoral Studies, 31:83-95.

Sonnemans, J. and Offerman, T. (2001). Is the quadratic scoring rule really incentive compatible? Working paper, University of Amsterdam.

Tyran, J.-R. (2004). Voting when money and morals conflict: an experimental test of expressive voting. Journal of Public Economics, 88(7-8):1645-1664.

Tyszler, M. and Schram, A. (2013). Strategic voting in heterogeneous electorates: An experimental study. Games, 4(4):624-647.

Williams, K. C. (1994). Spatial elections with endorsements and uninformed voters: Some laboratory experiments. Public Choice, 80(1-2):1-8. 


\section{Appendix A Experimental Procedures and Instructions}

The computerized experiment was run at the CREED laboratory of the University of Amsterdam. In total 336 undergraduate students participated in the experiment. About two fifths of the subjects were women ( $38 \%$ to be precise). After arrival in the lab's reception room, each subject drew a card to be randomly assigned to a seat in the laboratory. Once everyone was seated, the instructions for the experiment were given out. Subjects first received a set of general instructions that describe the game. After the general instructions subjects answered a few questions to ensure their understating of the game. Thereafter, they were told whether they had been assigned to the role of a voter or a candidate. Voters and candidates then received additional instructions explaining in greater detail their possible actions and payoffs. After these specific instructions, subjects answered a final set of control questions before starting to play the game. During the game in the $A G$ treatments, we provided candidates with a sheet of paper that could be used to keep track of the number of advocacy groups that were formed in each period. After the 24 periods of the game were over, subjects were paid their earnings in private and were dismissed. The average session lasted approximately 90 minutes.

The instructions used in the AG12 treatment (authors' translation from Dutch to English) are available in the online supplementary materials. The instructions for other treatments (in Dutch) are very similar and are also available upon request.

\section{Appendix B Illustration of the challenger's problem}

We illustrate the complex tradeoffs for a challenger in an example where the incumbent is positioned at location 12 and the challenger $j$ lost last period's election, where she was positioned at location 11. Assume further that she has not yet tried location 13 and that all voters vote sincerely. The past election outcome indicates that the voting equilibrium must be at locations $[12,15]$. She therefore considers which of the locations $[13,15]$ to choose (recall that $j$ cannot pick the incumbent's location 12 ). Let us denote by $p\left(\ell_{t}\right)$ challenger $j$ 's belief about the chance that location $\ell$ is the equilibrium in period $t$. Moreover, let $\pi$ be the fixed payoff from winning one election and $T>1$ denotes her expected number of periods until the next preference-shock occurs (or the number of remaining periods of the game). Let us first consider the expected, accumulated payoff (i.e., we assume risk neutrality and neglect any discounting) from the remaining $T$ periods, $E\left(\pi\left(\ell_{t}\right)\right)$, if $j$ chooses $\ell_{t}=13$ in period $t$. This is given by

$$
\begin{aligned}
E(\pi(13))= & p(13) \times(\pi \times T)+p(14)\left(\pi+q(14 \mid 13) \times 0+q(15 \mid 13)\left(\frac{1}{2} \pi+\frac{1}{2} \pi(T-2)\right)\right) \\
& +p(15)(\pi+q(14 \mid 13) \times \pi(T-2)+q(15 \mid 13) \times 0) \\
= & \pi\left(p(13) \times T+p(14)\left(1+\frac{q(15 \mid 13)}{2}(T-1)\right)+p(15)(1+q(14 \mid 13)(T-2))\right),
\end{aligned}
$$

for $T \geq 2$. The expected payoff consists of the expected earnings if the median were either at location (i) 13, (ii) 14, or (iii) 15 (the expected payoff from the incumbent being already at the median voter's location is $p(12) \times 0=0)$. In the first case $(\mathrm{i})$, if the median were at location 13 , 
she would earn payoff $\pi$ for $T$ periods. (ii) If the median were at location 14 (while she picked 13), $j$ would definitively win this period (as the incumbent is located at 12). However, in the following period she would be fixed at location 13. Her expected payoff would then be given by $q(14 \mid 13)$, her belief (conditional on $j$ positioning at 13) about the other candidate choosing the winning location 14 - which would allow him to win all remaining periods, leaving a payoff of zero for $j$ - and $q(15 \mid 13)$, her belief about the other candidate choosing location 15. For the latter case, voters would decide between candidates at 13 and 15 . With the median voter at 14 and a random vote split, $j$ would have a fifty percent chance of winning at 13. If $j$ wins, the other candidate would move to 14 in the subsequent period and would win all remaining elections. In case $j$ loses in $t+1$, she would move to 14 and would win all the remaining $(T-2)$ periods. Finally, (iii) if the median were at location $15, j$ would certainly win this period. If the other candidate would choose location 14 in period $t+1$, he would win the election. However, in the subsequent period, candidate $j$ would pick location 15 and would win all remaining $(T-2)$ elections.

Following the same logic, it is straightforward to derive $j$ 's expected payoffs if she was to choose location $\ell_{t}=14$ or $\ell_{t}=15$. Comparing the expected payoffs from these different options one notes that the choice is not only shaped by the challenger's expectations about the winning location but also by the beliefs regarding the other candidate's behavior and the number of remaining periods. In the $A G$ treatments, the challenger might have more information and, presumably, more accurate beliefs about the winning location. The formation of advocacy groups could also affect beliefs about the other candidate's behavior. Moreover, the challenger's decision will further depend on her expectations regarding the level of information obtained from advocacy groups in future periods.

This last point, i.e. the fact that both candidates will have more information in subsequent periods, renders the one-step strategy less attractive: if $j$ does not hit the equilibrium in the present period, she would allow her competitor to base his decision choice in $t+1$ on a larger information set, thus increasing his chances to position at the median. Stated differently, the myopic best response of making one step (and winning for sure) is less attractive and there are stronger incentives to immediately jump to the expected median. In turn, we should see larger jumps in the $A G$ treatments.

\section{Appendix C Additional Figures}

Figure C.1 shows the convergence paths of each session, the behavior of both candidates, and the location of the median voter. The outlier election can be seen at the end of AG12 session 1. 


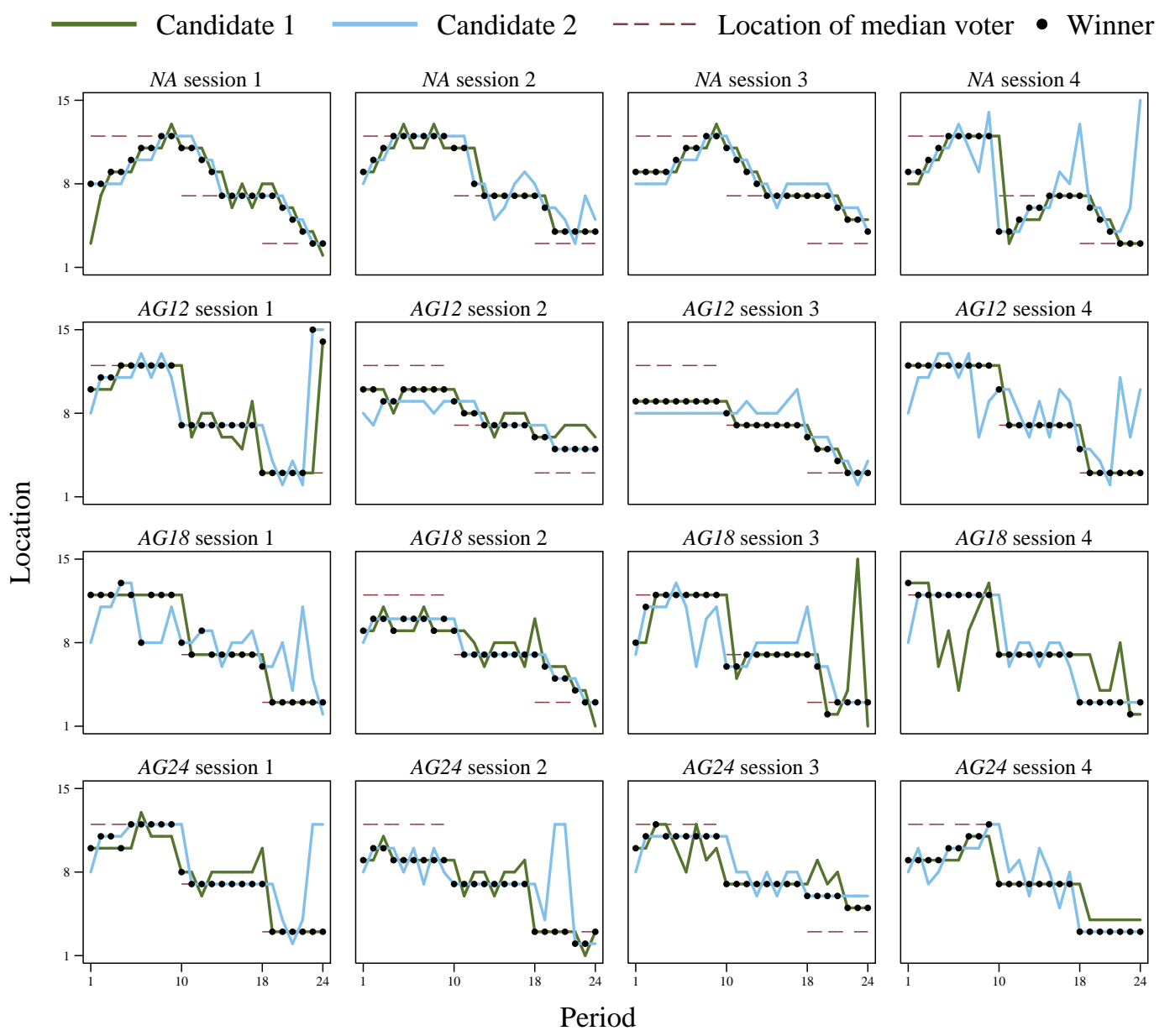

Figure C.1: Location of candidates 1 and 2 (green and blue lines) as well as the winning location (black dot) per session and period. The thin red line corresponds to the median voter locations. 